\title{
2-Substitution of Adenine Nucleotide Analogues Containing a Bicyclo[3.1.0]hexane Ring System Locked in a Northern Conformation: Enhanced Potency as $\mathrm{P} \mathrm{Y}_{1}$ Receptor Antagonists
}

\author{
Hak Sung Kim ${ }^{\dagger} \neq$, Michihiro Ohno ${ }^{\dagger}$, Bin Xu', Hea Ok Kim $\$$, Yongseok Choil , Xiao D. $\mathrm{Ji}^{\dagger}$, \\ Savitri Maddileti ${ }^{\wedge}$, Victor E. Marquez ${ }^{\|}$, T. Kendall Harden ${ }^{\wedge}$, and Kenneth A. Jacobson ${ }^{\dagger,{ }^{*}}$ \\ †Molecular Recognition Section, Laboratory of Bioorganic Chemistry, NIDDK, National Institutes \\ of Health, Department of Health and Human Services, Bethesda, Maryland 20892-0810 \\ $\S$ Division of Chemistry and Molecular Engineering, Seoul National University, Seoul 151-742, \\ Korea \\ "Laboratory of Medicinal Chemistry, Center for Cancer Research, $\mathrm{NCl}$-Frederick, National \\ Institutes of Health, Frederick, Maryland 21702 \\ 'Department of Pharmacology, School of Medicine, University of North Carolina, Chapel Hill, \\ North Carolina 27599-7365
}

\section{Abstract}

Preference for the northern $(N)$ ring conformation of the ribose moiety of adenine nucleotide $3^{\prime}$, $5^{\prime}$-bisphosphate antagonists of $\mathrm{P}_{2} \mathrm{Y}_{1}$ receptors was established by using a ring-constrained methanocarba (a bicyclo[3.1.0]hexane) ring as a ribose substitute (Nandanan et al. J. Med. Chem. 2000, 43, 829-842). We have now combined the ring-constrained $(N)$-methanocarba modification with other functionalities at the 2-position of the adenine moiety. A new synthetic route to this series of bisphosphate derivatives was introduced, consisting of phosphorylation of the pseudoribose moiety prior to coupling with the adenine base. The activity of the newly synthesized analogues was determined by measuring antagonism of 2-methylthio-ADP-stimulated phospholipase $\mathrm{C}$ (PLC) activity in $1321 \mathrm{~N} 1$ human astrocytoma cells expressing the recombinant human $\mathrm{P}_{2} \mathrm{Y}_{1}$ receptor and by using the radiolabeled antagonist $\left[{ }^{3} \mathrm{H}\right] 2$-chloro- $N^{6}$-methyl- $(N)$ methanocarba- $2^{\prime}$-deoxyadenosine $3^{\prime}, 5^{\prime}$-bisphosphate $\mathbf{5}$ in a newly developed binding assay in Sf9 cell membranes. Within the series of 2-halo analogues, the most potent molecule at the $\mathrm{hP} 2 \mathrm{Y}_{1}$ receptor was an $(N)$-methanocarba $N^{6}$-methyl-2-iodo analogue $\mathbf{1 2}$, which displayed a $K_{\mathrm{i}}$ value in competition for binding of $\left[{ }^{3} \mathrm{H}\right] 5$ of $0.79 \mathrm{nM}$ and a $K_{\mathrm{B}}$ value of $1.74 \mathrm{nM}$ for inhibition of PLC. Thus, $\mathbf{1 2}$ is the most potent antagonist selective for the $\mathrm{P}_{2} \mathrm{Y}_{1}$ receptor yet reported. The 2-iodo group was substituted with trimethyltin, thus providing a parallel synthetic route for the introduction of an iodo group in this high-affinity antagonist. The $(N)$-methanocarba-2-methylthio, 2-methylseleno, 2-hexyl, 2-(1-hexenyl), and 2-(1-hexynyl) analogues bound less well, exhibiting micromolar affinity at $\mathrm{P} 2 \mathrm{Y}_{1}$ receptors. An enzymatic method of synthesis of the $3^{\prime}, 5^{\prime}$ bisphosphate from the corresponding $3^{\prime}$-monophosphate, suitable for the preparation of a radiophosphorylated analogue, was explored. 


\section{Introduction}

Two families of $\mathrm{P} 2$ nucleotide receptors exist: $\mathrm{G}$ protein-coupled $\mathrm{P} 2 \mathrm{Y}$ receptors, of which

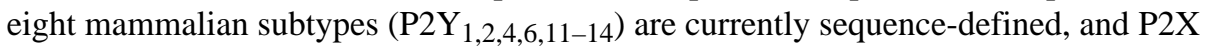
ligand-gated cation channels, of which seven mammalian subtypes $\left(\mathrm{P} 2 \mathrm{X}_{1-7}\right)$ have been cloned. ${ }^{1-4}$ Adenine nucleotides are required for activation of the $\mathrm{P} 2 \mathrm{Y}_{1}, \mathrm{P} 2 \mathrm{Y}_{11}, \mathrm{P} 2 \mathrm{Y}_{12}$, and $\mathrm{P} 2 \mathrm{Y}_{13}$ subtypes, and uracil nucleotides activate $\mathrm{P}_{2} \mathrm{Y}_{2}, \mathrm{P}_{2} \mathrm{Y}_{4}$, and $\mathrm{P} 2 \mathrm{Y}_{6}$, subtypes. The $\mathrm{P} 2 \mathrm{Y}_{2}$ receptor is equipotently activated by UTP and ATP. The most recently identified subtypes are the $\mathrm{P} 2 \mathrm{Y}_{13}$ receptor, which is present in the immune system, ${ }^{5}$ and the $\mathrm{P} 2 \mathrm{Y}_{14}$ receptor, which is activated by UDP-glucose. ${ }^{6}$ There is evidence that multiple P2Y receptors may be involved in the activation of eosinophils and neutrophils. ${ }^{7}$

The $\mathrm{P}_{2} \mathrm{Y}_{1}$ receptor is distributed in the heart, skeletal, and various smooth muscles and the prostate, ovary, brain, and circulating blood cells. ${ }^{8}$ This receptor was first cloned from chick brain; ${ }^{9}$ its regional brain distribution and presence in glial cells have been described, ${ }^{10-12}$ and abnormalities in $\mathrm{P}_{2} \mathrm{Y}_{1}$ receptor levels may exist in the brains of persons with Alzheimer's disease. ${ }^{13}$ Activation of this receptor by ADP mediates relaxation in the guinea pig aorta. ${ }^{14}$ The $\mathrm{P}_{2} \mathrm{Y}_{1}$ receptor plays a major physiological role in platelet aggregation. ${ }^{15}$

$\mathrm{P} 2 \mathrm{Y}$ receptor ligands are being explored for therapeutic applications in the cardiovascular, endocrine, and other systems. The $\mathrm{P}_{2} \mathrm{Y}_{1}$ and $\mathrm{P} 2 \mathrm{Y}_{12}$ receptors are the furthest advanced in the P2Y family with respect to selective agonists and antagonists. ${ }^{16-26} 3^{\prime}, 5^{\prime}$-Bisphosphate nucleotides have been developed as selective antagonists of the $\mathrm{P} 2 \mathrm{Y}_{1}$ receptor, and high receptor affinities have been achieved in this series. ${ }^{20}$ The $2^{\prime}$-deoxyribose moiety of widely used P2 $\mathrm{Y}_{1}$ receptor antagonists such as $N^{6}$-methyl-2' ${ }^{\prime}$-deoxyadenosine $3^{\prime}, 5^{\prime}$-bisphosphate 1 may be replaced with carbocyclics, smaller and larger rings, acyclics, and conformationally constrained rings, ${ }^{17-19}$ resulting in retention or enhancement of affinity for the receptor. A 2-chloro group was found to enhance potency and selectivity in the case of nucleotide $\mathbf{2}$ and the acyclic bisphosphate analogue 3. ${ }^{19,27}$ An acyclic bisphosphonate analogue $\mathbf{4}$ was also shown to be a $\mathrm{P} 2 \mathrm{Y}_{1}$ receptor antagonist. ${ }^{19}$<smiles>[R]c1nc(NC)c2ncn([C@@H]3C[C@H](OP(=O)(O)O)[C@@H](COP(=O)(O)O)O3)c2n1</smiles>

$1 \mathrm{R}=\mathrm{H}$

$2 \mathrm{R}=\mathrm{Cl}$<smiles>CNc1nc(Cl)nc2c1ncn2C1C2CC3(COP(=O)(O)O)C(OP(=O)(O)O)C2C13</smiles>

5

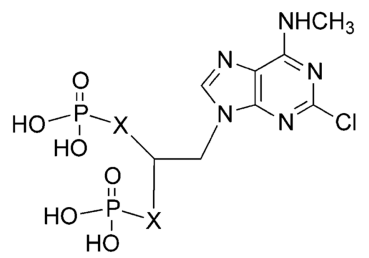

$$
3 \mathrm{X}=\mathrm{OCH}_{2}
$$$$
4 \mathrm{X}=\mathrm{CH}_{2}
$$

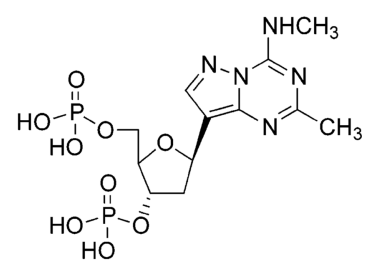

6

The most recently introduced $\mathrm{P}_{2} \mathrm{Y}_{1}$ receptor antagonists contain novel substitutions of the ribose moiety or of the adenine ring system. In solution, the conformation of the ribose ring of nucleosides and nucleotides exists in a rapid, dynamic two-state equilibrium between a $(N)$ (northern, $2^{\prime}$-exo) or $(S)$ (southern, $2^{\prime}$-endo) conformation, although their target 
receptors probably prefer specific conformations. We have replaced the ribose moiety for $\mathrm{P}_{2} \mathrm{Y}_{1}$ antagonists with a carbocyclic ring locked in a preferred conformation, a fusion of cyclopropane and cyclopentane rings known as the methanocarba modification. ${ }^{28-30}$ Two structural variations, depending on the position of the cyclopropane ring, restrict the ring pucker, i.e., hold the riboselike ring (pseudosugar) in either a $(N)$ - or $(S)$-envelope conformation, as defined in the pseudorotational cycle. A prototypical ring-constrained $\mathrm{P} 2 \mathrm{Y}_{1}$ antagonist is the highly potent $(N)$-methanocarba derivative 2-chloro- $N^{6}$-methyl- $(N)$ methanocarba-2' -deoxyadenosine $3^{\prime}, 5^{\prime}$-bisphosphate $5 .{ }^{18,20}$ This molecule was also prepared in $\left[{ }^{3} \mathrm{H}\right]$-labeled form and provides the first broadly reliable high-affinity antagonist for quantitation of a $\mathrm{P} 2 \mathrm{Y}$ receptor in a radioligand binding assay. ${ }^{31}$ The recently reported Cnucleoside pyrazolo[1,5-a]-1,3,5-triazine bisphosphate $\mathbf{6}$ is also a potent $\mathrm{P}_{2} \mathrm{Y}_{1}$ antagonist. ${ }^{25}$

In the present study, we combined the ring-constrained $(N)$-methanocarba modification of adenine nucleotides with other adenine 2-position functionalities to prepare novel analogues, which were evaluated for affinity at the human $\mathrm{P}_{2} \mathrm{Y}_{1}$ receptor. In one case, a 2-iodo substitution conferred a significant increase in antagonist potency. New synthetic routes to antagonists in this series, including methods for introduction of phosphate groups as either the terminal step or prior to the coupling of sugar and nucleobase, were explored. The 2-iodo substituent could also be introduced at various stages of the synthesis.

\section{Experimental Section}

\section{Chemical Synthesis}

Nucleosides and synthetic reagents were purchased from Sigma Chemical Co. (St. Louis, MO) and Aldrich (Milwaukee, WI). 2,6-Dichloropurine was obtained from Sigma. The protected intermediate 19 was synthesized in our laboratory as described. ${ }^{45} 5$ and 9 were prepared as described. ${ }^{18} 37$ and $\mathbf{3 8}$ were prepared as described. ${ }^{37}$

${ }^{1} \mathrm{H}$ NMR spectra were obtained with a Varian Gemini-300 spectrometer ( $300 \mathrm{MHz}$ ) with $\mathrm{D}_{2} \mathrm{O}, \mathrm{CDCl}_{3}, \mathrm{CD}_{3} \mathrm{OD}$, and $\mathrm{DMSO} d_{6}$ as a solvent. Tetramethylsilane (TMS) was the external standard. ${ }^{31} \mathrm{P}$ NMR spectra were recorded at room temperature with a Varian XL-300 spectrometer (121.42 MHz); orthophosphoric acid (85\%) was used as an external standard.

Purity of compounds was checked with a Hewlett-Packard 1100 HPLC apparatus equipped with a Luna $5 \mu \mathrm{C} 18(2)$ analytical column $(250 \times 4.6 \mathrm{~mm}$, Phenomenex, Torrance, CA) in two solvent systems.

System A: linear gradient solvent system, $0.1 \mathrm{M}$ TEAA/ $\mathrm{CH}_{3}-\mathrm{CN}$ from $95 / 5$ to $40 / 60$ in 20 $\mathrm{min}$; the flow rate was $1 \mathrm{~mL} / \mathrm{min}$.

System B: linear gradient solvent system, $5 \mathrm{mM}$ TBAP/CH $3-\mathrm{CN}$ from $80 / 20$ to $40 / 60$ in 20 $\mathrm{min}$; the flow rate was $1 \mathrm{~mL} / \mathrm{min}$.

Peaks were detected by UV absorption with a diode array detector. All derivatives tested for biological activity showed $\geq 97 \%$ purity in the HPLC systems.

Low-resolution CI-NH 3 (chemical ionization) mass spectra were measured with a Finnigan 4600 mass spectrometer, and high-resolution EI (electron impact) mass spectrometry was performed with a VG7070F mass spectrometer at $6 \mathrm{kV}$. High-resolution FAB (fast atom bombardment) mass spectrometry was performed with a JEOL SX102 spectrometer with 6$\mathrm{kV}$ Xe atoms following desorption from a glycerol matrix. 
Purification of the nucleotide analogues for biological testing was carried out on SephadexDEAE-A-25 resin columns with a linear gradient $(0.01-0.5 \mathrm{M})$ of $0.5 \mathrm{M}$ ammonium bicarbonate applied as the mobile phase.

\section{(1'R,2'S,4'S,5'S)-4-(6-Amino-2-iodo-9H-purin-9-yl)-1-[(phosphato)methyl]-2- (phosphato)bicyclo[3.1.0]-hexane Tetraammonium Salt (7)}

Compound 29 (1.48 mg, $0.0023 \mathrm{mmol})$ was dissolved in $30 \% \mathrm{NH}_{3}$ in water $(0.50 \mathrm{~mL})$ and stirred for $6.5 \mathrm{~h}$ at $60^{\circ} \mathrm{C}$ in a sealed tube. The solvent was removed under reduced pressure.

Purification of the obtained residue was performed on an ion-exchange column packed with Sephadex-DEAE A-25 resin. A linear gradient (0.01-0.5 M) of $0.5 \mathrm{M}$ ammonium bicarbonate was applied as the mobile phase, and UV and HPLC were used to monitor the elution, which furnished $7(0.77 \mathrm{mg}, 54 \%):{ }^{1} \mathrm{H}$ NMR $\left(\mathrm{D}_{2} \mathrm{O}\right) \delta 8.58(\mathrm{~s}, 1 \mathrm{H}), 5.20-4.80(\mathrm{~m}$, $2 \mathrm{H}), 4.60-4.40(\mathrm{~m}, 1 \mathrm{H}), 3.60-3.56(\mathrm{~m}, 1 \mathrm{H}), 2.35-2.20(\mathrm{~m}, 1 \mathrm{H}), 2.00-1.88(\mathrm{~m}, 1 \mathrm{H}), 1.88$ $1.80(\mathrm{~m}, 1 \mathrm{H}), 1.18-1.12(\mathrm{~m}, 1 \mathrm{H}), 0.99-0.91(\mathrm{~m}, 1 \mathrm{H}) ;{ }^{31} \mathrm{P}$ NMR $\left(\mathrm{D}_{2} \mathrm{O}\right) \delta 0.17,-0.25\left(2 \mathrm{~s}, 3^{\prime}-\right.$ $\left.\mathrm{P}, 5^{\prime}-\mathrm{P}\right)$; MS $(\mathrm{m} / \mathrm{e})$ (negative-FAB) $546\left(\mathrm{M}^{+}-1\right)$; HRMS (negative-FAB) calcd for $\mathrm{C}_{12} \mathrm{H}_{15} \mathrm{~N}_{5} \mathrm{O}_{8} \mathrm{P}_{2} \mathrm{I}$ 545.9441, found 545.9454; HPLC $8.3 \mathrm{~min}$ (99\%) (system A), $14.3 \mathrm{~min}$ (99\%) (system B).

(1'R,2' S,4'S,5'S)-4-(6-Amino-2-methylthio-9H-purin-9-yl)-1-[(phosphato)methyl]-2(phosphato)bicyclo[3.1.0]-hexane Tetraammonium Salt (8)

To a solution of $26(1.70 \mathrm{mg}, 0.0020 \mathrm{mmol})$ in $\mathrm{CH}_{2} \mathrm{Cl}_{2}(0.30 \mathrm{~mL})$ was added $1.0 \mathrm{M} \mathrm{BCl}_{3}$ in $\mathrm{CH}_{2} \mathrm{Cl}_{2}(0.50 \mathrm{~mL})$ and the mixture stirred for $2 \mathrm{~d}$ at $5{ }^{\circ} \mathrm{C}$. The reaction was quenched upon addition of $5.0 \mathrm{~mL}$ of triethylammonium bicarbonate buffer $(1.0 \mathrm{M})$. The mixture was subsequently frozen and lyophilized, which furnished crude $8(1.90 \mathrm{mg})$ : MS $(\mathrm{m} / \mathrm{e})$ (negative-FAB) 485, 487 (peak height ratio = 3:1) $\left(\mathrm{M}_{+}-1\right)$; HPLC $15.6 \mathrm{~min}(99 \%)$ (system B).

The crude sample of $\mathbf{8}(1.90 \mathrm{mg})$ was dissolved in $30 \% \mathrm{NH}_{3}$ in water $(3.0 \mathrm{~mL})$ and stirred for $2 \mathrm{~h}$ at $70{ }^{\circ} \mathrm{C}$ in a sealed tube. The solvent was removed under reduced pressure, the obtained residue was purified on an ion-exchange column packed with Sephadex-DEAE A-25 resin, a linear gradient $(0.01-0.5 \mathrm{M})$ of $0.5 \mathrm{M}$ ammonium bicarbonate was applied as the mobile phase, and UV and HPLC were used to monitor the elution, which furnished homogeneous $8(1.90 \mathrm{mg}, 94 \%):{ }^{1} \mathrm{H}$ NMR $\left(\mathrm{D}_{2} \mathrm{O}\right) \delta 8.44(\mathrm{~s}, 1 \mathrm{H}), 5.30-5.20(\mathrm{~m}, 1 \mathrm{H}), 5.09(\mathrm{~d}$, $1 \mathrm{H}, J=6.5 \mathrm{~Hz}), 4.90-4.75(\mathrm{~m}, 1 \mathrm{H}), 3.70-3.55(\mathrm{~m}, 1 \mathrm{H}), 2.60(\mathrm{~s}, 3 \mathrm{H}), 2.30-2.20(\mathrm{~m}, 1 \mathrm{H})$, $2.00-1.94(\mathrm{~m}, 1 \mathrm{H}), 1.85-1.80(\mathrm{~m}, 1 \mathrm{H}), 1.17-1.14(\mathrm{~m}, 1 \mathrm{H}), 0.96-0.94(\mathrm{~m}, 1 \mathrm{H}) ;{ }^{31} \mathrm{P} \mathrm{NMR}$ $\left(\mathrm{D}_{2} \mathrm{O}\right) \delta 2.03,1.36\left(2 \mathrm{~s}, 3^{\prime}-\mathrm{P}, 5^{\prime}-\mathrm{P}\right)$; MS $(\mathrm{m} / \mathrm{e})$ (negative-FAB) $466\left(\mathrm{M}^{+}-1\right)$; HRMS (negative-FAB) calcd for $\mathrm{C}_{13} \mathrm{H}_{18} \mathrm{~N}_{5} \mathrm{O}_{8} \mathrm{P}_{2} \mathrm{~S} 466.0374$, found 466.0363; HPLC $8.7 \mathrm{~min}$ (99\%) in solvent system A, 14.1 min (99\%) in a solvent system B.

\section{(1'R,2'S,4'S,5'S)-4-(2-Fluoro-6-methylamino-9H-purin-9-yl)-1-[(phosphato)methyl]-2- (phosphato)bicyclo[3.1.0]-hexane Tetraammonium Salt (10)}

The mixture of $44(5 \mathrm{mg}, 0.0074 \mathrm{mmol})$ in $5 \% \mathrm{TFA} / \mathrm{CH}_{2} \mathrm{Cl}_{2}(5 \mathrm{~mL})$ was stirred at room temperature for $3 \mathrm{~h}$. After solvent was removed, the residue was treated with triethylammonium bicarbonate buffer $(1 \mathrm{M}, 0.5 \mathrm{~mL})$ and stirred for $30 \mathrm{~min}$. The aqueous layer was washed twice with $\mathrm{CH}_{2} \mathrm{Cl}_{2}$ and evaporated to dryness under reduced pressure. The residue was purified with ion-exchange column chromatography with the use of SephadexDEAE-A-25 resin with a linear gradient $(0.01-0.5 \mathrm{M})$ of $0.5 \mathrm{M} \mathrm{NH}_{4}-\mathrm{HCO}_{3}$ as the mobile phase. After lyophilization, $10(1.38 \mathrm{mg}, 36 \%)$ was obtained as a white solid: ${ }^{1} \mathrm{H}$ NMR $\left(\mathrm{D}_{2} \mathrm{O}\right) \delta 8.25(\mathrm{~s}, 1 \mathrm{H}), 5.25-5.1(\mathrm{~m}, 2 \mathrm{H}), 3.8-3.65(\mathrm{~m}, 2 \mathrm{H}), 3.05(\mathrm{~s}, 3 \mathrm{H}), 2.4-2.1(1 \mathrm{H}), 2.1-$ $1.9(\mathrm{~m}, 2 \mathrm{H}), 1.1-0.9(1 \mathrm{H}) ;{ }^{31} \mathrm{P}$ NMR $\left(\mathrm{D}_{2} \mathrm{O}\right) 0.878(\mathrm{~s}), 1.2(\mathrm{~s})$; HRMS $(\mathrm{m} / \mathrm{e})$ (negative-FAB) 
calcd for $\mathrm{C}_{13} \mathrm{H}_{18} \mathrm{FN}_{5} \mathrm{O}_{8} \mathrm{P}_{2}$ 452.0536, found 452.0548; HPLC 8.2 (99\%) min in solvent system A, $16.1 \mathrm{~min}(99 \%)$ in solvent system B.

(1'R,2'S,4'S,5'S)-[4-(2-Bromo-6-methylamino-9H-purin-9-yl)-1-[(phosphato)methyl]-2(phosphato)bicyclo[3.1.0]-hexane Tetraammonium Salt (11)

The mixture of $45(3.0 \mathrm{mg}, 0.0041 \mathrm{mmol})$ in $5 \% \mathrm{TFA} / \mathrm{CH}_{2} \mathrm{Cl}_{2}(5 \mathrm{~mL})$ was stirred at room temperature for $3 \mathrm{~h}$. After removal of the solvent, the residue was treated with triethylammonium bicarbonate buffer $(1 \mathrm{M}, 0.5 \mathrm{~mL})$ and stirred for $30 \mathrm{~min}$. The aqueous layer was washed twice with $\mathrm{CH}_{2} \mathrm{Cl}_{2}$ and evaporated to dryness. The residue was purified with ion-exchange column chromatography with the use of Sephadex-DEAE-A-25 resin with a linear gradient $(0.01-0.5 \mathrm{M})$ of $0.5 \mathrm{M} \mathrm{NH}_{4} \mathrm{HCO}_{3}$ as the mobile phase. After lyophilization, $11(1.36 \mathrm{mg}, 58 \%)$ was obtained as a white solid: ${ }^{1} \mathrm{H}$ NMR $\left(\mathrm{D}_{2} \mathrm{O}\right) \delta 8.42$ (s, $1 \mathrm{H}), 5.4-5.1(\mathrm{~m}, 2 \mathrm{H}), 3.8-3.6(\mathrm{~m}, 2 \mathrm{H}), 3.1(\mathrm{~s}, 3 \mathrm{H}), 2.4-2.1(\mathrm{~m}, 2 \mathrm{H}), 2.1-1.8(\mathrm{~m}, 2 \mathrm{H}), 1.1-$ $0.9(1 \mathrm{H}) ;{ }^{31} \mathrm{P}$ NMR $\left(\mathrm{D}_{2} \mathrm{O}\right) \delta 0.4(\mathrm{~s}), 0.9(\mathrm{~s})$; HRMS $(\mathrm{m} / \mathrm{e})$ (negative-FAB) calcd for $\mathrm{C}_{13} \mathrm{H}_{18} \mathrm{BrN}_{5} \mathrm{O}_{8} \mathrm{P}_{2}$ 511.9736, found 511.9763; HPLC $9.3 \mathrm{~min}$ (99\%) in solvent system A, $14.5 \mathrm{~min}(99 \%)$ in solvent system B.

(1'R,2' S,4'S,5'S)-4-(2-lodo-6-methylaminopurin-9-yl)-1-[(phosphato)methyl]-2(phosphato)bicyclo[3.1.0]-hexane (12)

Method A-Compound 29 (3.61 mg, $0.0057 \mathrm{mmol}$ ) was dissolved in $40 \% \mathrm{MeNH}_{2}$ in water $(2.0 \mathrm{~mL})$ and stirred for $26 \mathrm{~h}$ at room temperature. The solvent was removed under reduced pressure. Purification of the obtained residue was performed on an ion-exchange column packed with Sephadex-DEAE A-25 resin, a linear gradient (0.01-0.5 M) of $0.5 \mathrm{M}$ ammonium bicarbonate was applied as the mobile phase, and UV and HPLC were used to monitor the elution, which furnished $\mathbf{1 2}(0.73 \mathrm{mg}, 20 \%)$.

Method B-A solution of the 2-iodo bis(di-tert-butyl phosphate) derivative 46 (7.1 mg, $9.03 \mu \mathrm{mol})$ in $5 \%$ trifluoroacetic acid in methylene chloride was stirred for $2 \mathrm{~h}$ at room temperature. All volatile material was removed in vacuo. The residue was purified by using ion-exchange column chromatography on Sephadex-DEAE-25 resin and a linear gradient $(0-0.5 \mathrm{M})$ of $0.5 \mathrm{M}$ ammonium bicarbonate as the mobile phase to give the 2-iodo bisphosphate derivative $\mathbf{1 2}(2.9 \mathrm{mg}, 55 \%)$ as an ammonium salt: ${ }^{1} \mathrm{H}$ NMR $\left(\mathrm{D}_{2} \mathrm{O}\right) \delta 8.54$ (bs, $1 \mathrm{H}), 5.19(\mathrm{~m}, 1 \mathrm{H}), 5.01(\mathrm{~d}, 1 \mathrm{H}, J=6.9 \mathrm{~Hz}), 4.58(\mathrm{dd}, 1 \mathrm{H}, J=4.7,11.3 \mathrm{~Hz}), 3.73(\mathrm{dd}, 1 \mathrm{H}, J$ $=4.4,11.0 \mathrm{~Hz}), 3.07(\mathrm{bs}, 3 \mathrm{H}), 2.28(\mathrm{dd}, 1 \mathrm{H}, J=7.7,14.6 \mathrm{~Hz}), 1.92-2.09(\mathrm{~m}, 2 \mathrm{H}), 1.26(\mathrm{dd}$, $1 \mathrm{H}, J=4.1,6.1 \mathrm{~Hz}), 1.06(\mathrm{dd}, 1 \mathrm{H}, J=9.7,16.3 \mathrm{~Hz}) ;{ }^{31} \mathrm{P}$ NMR $\left(\mathrm{D}_{2} \mathrm{O}\right) 0.651(\mathrm{~s}) ; \mathrm{HRMS}$ (negative-ion $\mathrm{FAB}$ ) calcd for $\mathrm{C}_{13} \mathrm{H}_{17} \mathrm{~N}_{5} \mathrm{O}_{8} \mathrm{P}_{2} \mathrm{I} 559.9597$, found 559.9604; HPLC $9.8 \mathrm{~min}$ $(97 \%)$ in solvent system A, 15.4 min $(97 \%)$ in system B.

\section{(1'R,2' S,4'S,5'S)-4-(6-Methylamino-2-methylthio-9H-purin-9-yl)-1-[(phosphato)methyl]-2- (phosphato)bicyclo-[3.1.0]hexane Tetraammonium Salt (13)}

To a solution of $28(4.2 \mathrm{mg}, 0.0050 \mathrm{mmol})$ in $\mathrm{CH}_{2} \mathrm{Cl}_{2}(0.30 \mathrm{~mL})$ was added $1.0 \mathrm{M} \mathrm{BCl}_{3}$ in $\mathrm{CH}_{2} \mathrm{Cl}_{2}(0.60 \mathrm{~mL})$ and the mixture stirred for $2 \mathrm{~d}$ at $5{ }^{\circ} \mathrm{C}$. The reaction was quenched upon the addition of $5.0 \mathrm{~mL}$ of triethylammonium bicarbonate buffer $(1.0 \mathrm{M})$. The mixture was subsequently frozen and lyophilized.

Purification of the obtained residue was performed on an ion-exchange column packed with Sephadex-DEAE A-25 resin, a linear gradient (0.01-0.5 M) of $0.5 \mathrm{M}$ ammonium bicarbonate was applied as the mobile phase, and UV and HPLC were used to monitor the elution, which furnished $13(1.69 \mathrm{mg}, 81 \%):{ }^{1} \mathrm{H}$ NMR $\left(\mathrm{D}_{2} \mathrm{O}\right) \delta 8.45(\mathrm{~s}, 1 \mathrm{H}), 5.25-5.15(\mathrm{~m}$, $1 \mathrm{H}), 5.08-5.02(\mathrm{~m}, 1 \mathrm{H}), 4.65-4.60(\mathrm{~m}, 1 \mathrm{H}), 3.65-3.55(\mathrm{~m}, 1 \mathrm{H}), 3.13(\mathrm{bs}, 3 \mathrm{H}), 2.62(\mathrm{~s}, 3 \mathrm{H})$, $2.30-2.20(\mathrm{~m}, 1 \mathrm{H}), 2.00-1.85(\mathrm{~m}, 1 \mathrm{H}), 1.85-1.75(\mathrm{~m}, 1 \mathrm{H}), 1.15-1.10(\mathrm{~m}, 1 \mathrm{H}), 1.00-0.95$ 
(m, 1H); ${ }^{31} \mathrm{P}$ NMR $\left(\mathrm{D}_{2} \mathrm{O}\right) \delta 2.21,2.90\left(2 \mathrm{~s}, 3^{\prime}-\mathrm{P}, 5^{\prime}-\mathrm{P}\right) ; \mathrm{MS}(\mathrm{m} / \mathrm{e})$ (negative-FAB $) 480\left(\mathrm{M}^{+}\right.$ - 1); HRMS (negative-FAB) calcd for $\mathrm{C}_{14} \mathrm{H}_{20} \mathrm{~N}_{5} \mathrm{O}_{8} \mathrm{P}_{2} \mathrm{~S} 480.0488$, found 480.0498; HPLC $10.3 \mathrm{~min}(99 \%)$ in solvent system A, $16.4 \mathrm{~min}(99 \%)$ in solvent system B.

\section{(1'R,2'S,4'S,5'S)-4-(6-Methylamino-2-methylselenopurin-9-yl)-1-[(phosphato)methyl]-2- (phosphato)bicyclo-[3.1.0]hexane Tetraammonium Salt (14)}

Compound $30(0.38 \mathrm{mg}, 0.63 \mu \mathrm{mol})$ was dissolved in $40 \% \mathrm{MeNH}_{2}$ in water $(3.0 \mathrm{~mL})$ and stirred for $8 \mathrm{~h}$ at $80^{\circ} \mathrm{C}$. The solvent was removed under reduced pressure. Purification of the obtained residue was performed on an ion-exchange column packed with Sephadex-DEAE A-25 resin, a linear gradient $(0.01-0.5 \mathrm{M})$ of $0.5 \mathrm{M}$ ammonium bicarbonate was applied as the mobile phase, and UV and HPLC were used to monitor the elution, which furnished 14 (0.30 mg, 79\%): ${ }^{1} \mathrm{H}$ NMR $\left(\mathrm{D}_{2} \mathrm{O}\right) \delta 8.51(\mathrm{~s}, 1 \mathrm{H}), 5.10-5.00(\mathrm{~m}, 1 \mathrm{H}), 5.00-4.90(\mathrm{~m}, 1 \mathrm{H})$, 4.74-4.72 (m, 1H), 3.65-3.50 (m, 1H), $3.14(\mathrm{bs}, 3 \mathrm{H}), 2.53(\mathrm{~s}, 3 \mathrm{H}), 2.40-2.18(\mathrm{~m}, 1 \mathrm{H}), 2.05-$ $1.85(\mathrm{~m}, 1 \mathrm{H}), 1.85-1.75(\mathrm{~m}, 1 \mathrm{H}), 1.25-1.14(\mathrm{~m}, 1 \mathrm{H}), 1.00-0.95(\mathrm{~m}, 1 \mathrm{H}) ;{ }^{31} \mathrm{P}$ NMR $\left(\mathrm{D}_{2} \mathrm{O}\right) \delta$ $3.00,3.53$ (2s, $\left.3^{\prime}-\mathrm{P}, 5^{\prime}-\mathrm{P}\right)$; MS ( $\left.\mathrm{m} / \mathrm{e}\right)$ (negative-FAB) $528\left(\mathrm{M}^{+}-1\right)$, HRMS (negative-FAB) calcd for $\mathrm{C}_{14} \mathrm{H}_{20} \mathrm{~N}_{5} \mathrm{O}_{8} \mathrm{P}_{2}$ Se 527.9948, found 527.9950; HPLC $10.8 \mathrm{~min}(99 \%)$ in solvent system A, $16.8 \mathrm{~min}(99 \%)$ in solvent system B.

(1'R,2'S,4'S,5'S)-Phosphoric Acid [4-(2-Methyl-6-methylaminopurin-9-yl)-1phosphonooxymethylbicyclo[3.1.0]-hex-2-yl] Monoester (15)

A solution of $47(8.0 \mathrm{mg}, 0.012 \mathrm{mmol})$ in $5 \% \mathrm{TFA} / \mathrm{CH}_{2} \mathrm{Cl}_{2}(2.0 \mathrm{~mL})$ was stirred for $3 \mathrm{~h}$ at $25{ }^{\circ} \mathrm{C}$. The solvent was removed under reduced pressure and the residue was quenched by addition of $5.0 \mathrm{~mL}$ of triethylammonium bicarbonate buffer $(1.0 \mathrm{M})$. The mixture was subsequently frozen and lyophilized. Purification of the obtained residue was performed on an ion-exchange column packed with Sephadex-DEAE A-25 resin, a linear gradient (0.01$0.5 \mathrm{M}$ ) of $0.5 \mathrm{M}$ ammonium bicarbonate was applied as the mobile phase, and UV and HPLC were used to monitor the elution, which furnished $15(4.5 \mathrm{mg}, 73 \%):{ }^{1} \mathrm{H}$ NMR $\left(\mathrm{D}_{2} \mathrm{O}\right)$ $\delta 8.45(\mathrm{~s}, 1 \mathrm{H}), 5.18(\mathrm{~m}, 1 \mathrm{H}), 5.00(\mathrm{~d}, 1 \mathrm{H}, J=5.4 \mathrm{~Hz}), 4.57-4.50(\mathrm{~m}, 1 \mathrm{H}), 3.69-3.62(\mathrm{~m}$, $1 \mathrm{H}), 3.13(\mathrm{~s}, 3 \mathrm{H}), 2.53(\mathrm{~s}, 3 \mathrm{H}), 2.30-2.20(\mathrm{~m}, 1 \mathrm{H}), 2.24-1.92(\mathrm{~m}, 1 \mathrm{H}), 1.88(\mathrm{~m}, 1 \mathrm{H}), 1.19$ $(\mathrm{m}, 1 \mathrm{H}), 0.98(\mathrm{~m}, 1 \mathrm{H}) ;{ }^{31} \mathrm{P} N \mathrm{NMR}\left(\mathrm{D}_{2} \mathrm{O}\right) \delta 1.05,0.65\left(2 \mathrm{~s}, 3^{\prime}-\mathrm{P}, 5^{\prime}-\mathrm{P}\right)$; MS $(\mathrm{m} / \mathrm{e})$ (negativeFAB) $448\left(\mathrm{M}^{+}-1\right)$; HRMS (negative-FAB) calcd for $\mathrm{C}_{14} \mathrm{H}_{20} \mathrm{~N}_{5} \mathrm{O}_{8} \mathrm{P}_{2} 448.0787$, found 448.0807; HPLC 7.3 min (99\%) (system A), 14.2 min (99\%) (system B).

(1'R,2' S,4'S,5'S)-4-(2-Hexyl-6-methylaminopurin-9-yl)-1-[(phosphato)methyl]-2(phosphato)bicyclo[3.1.0]-hexane (16)

The 2-hexanyl bisphosphate derivative $\mathbf{1 6}(5.6 \mathrm{mg}, 69 \%)$ was prepared by the same method as above for 11, except the 2-hexanyl bis(di-tert-butyl phosphate) derivative $\mathbf{4 8}$ (11.2 $\mathrm{mg}$, $0.015 \mathrm{mmol}$ ) was used as the starting material: ${ }^{1} \mathrm{H}$ NMR $\left(\mathrm{D}_{2} \mathrm{O}\right) \delta 8.54(\mathrm{bs}, 1 \mathrm{H}), 5.23(\mathrm{~m}$, $1 \mathrm{H}), 5.10(\mathrm{~d}, 1 \mathrm{H}, J=6.6 \mathrm{~Hz}), 4.57(\mathrm{dd}, 1 \mathrm{H}, J=5.2,11.3 \mathrm{~Hz}), 3.70(\mathrm{~m}, 1 \mathrm{H}), 3.25(\mathrm{bs}, 3 \mathrm{H})$, 2.85 (dd, $2 \mathrm{H}, J=7.4,7.7 \mathrm{~Hz}), 2.29$ (dd, 1H, $J=7.7,15.1 \mathrm{~Hz}), 2.03(\mathrm{dt}, 1 \mathrm{H}, J=6.6,16.8$ $\mathrm{Hz}), 1.92(\mathrm{dd}, 1 \mathrm{H}, J=3.8,9.1 \mathrm{~Hz}), 1.773(\mathrm{~m}, 2 \mathrm{H}), 1.13-1.43(\mathrm{~m}, 9 \mathrm{H}), 1.03(\mathrm{dd}, 1 \mathrm{H}, J=6.6$, $7.7 \mathrm{~Hz}), 0.85(\mathrm{~m}, 3 \mathrm{H}) ;{ }^{31} \mathrm{P}$ NMR $\left(\mathrm{D}_{2} \mathrm{O}\right) 0.827(\mathrm{~s}), 0.375(\mathrm{~s})$; HRMS (negative-ion FAB) calcd for $\mathrm{C}_{19} \mathrm{H}_{30} \mathrm{~N}_{5} \mathrm{O}_{8} \mathrm{P}_{2}$ 518.1570, found 518.1544; HPLC $13.2 \mathrm{~min}(98 \%)$ in solvent system A, 16.6 min (97\%) in system B.

(1'R,2'S,4'S,5'S)-4-(2-Hex-1-ynyl-6-methylaminopurin-9-yl)-1-[(phosphato)methyl]-2(phosphato)bicyclo[3.1.0]-hexane (17)

The 2-hexenyl bisphosphate derivative 17 (3.2 $\mathrm{mg}, 68 \%$ ) was prepared by the same method as above for 11, except the 2-hexenyl bis(di-tert-butyl phosphate) derivative $49(6.0 \mathrm{mg}$, $8.08 \mu \mathrm{mol})$ was used as the starting material: ${ }^{1} \mathrm{H}$ NMR $\left(\mathrm{D}_{2} \mathrm{O}\right) \delta 8.54(\mathrm{~s}, 1 \mathrm{H}), 7.18(\mathrm{dt}, 1 \mathrm{H}, J$ $=7.1,15.4 \mathrm{~Hz}), 6.45(\mathrm{~m}, 1 \mathrm{H}), 5.22(\mathrm{~m}, 1 \mathrm{H}), 5.08(\mathrm{~d}, 1 \mathrm{H}, J=6.3 \mathrm{~Hz}), 4.57(\mathrm{dd}, 1 \mathrm{H}, J=4.7$, 
$11.0 \mathrm{~Hz}), 3.71(\mathrm{dd}, 1 \mathrm{H}, J=5.0,10.7 \mathrm{~Hz}), 3.22(\mathrm{bs}, 3 \mathrm{H}), 2.23-2.44(\mathrm{~m}, 3 \mathrm{H}), 2.03(\mathrm{~m}, 1 \mathrm{H})$, $1.95(\mathrm{dd}, 1 \mathrm{H}, J=3.7,8.8 \mathrm{~Hz}), 1.32-1.61(\mathrm{~m}, 4 \mathrm{H}), 1.24(\mathrm{dd}, 1 \mathrm{H}, J=4.1,5.5 \mathrm{~Hz}), 1.05(\mathrm{dd}$, $1 \mathrm{H}, J=6.3,8.2 \mathrm{~Hz}), 0.94(\mathrm{~m}, 3 \mathrm{H}) ;{ }^{31} \mathrm{P}$ NMR $\left(\mathrm{D}_{2} \mathrm{O}\right) 0.601(\mathrm{~s}), 0.299(\mathrm{~s})$; HRMS (negativeion $\mathrm{FAB}$ ) calcd for $\mathrm{C}_{19} \mathrm{H}_{28} \mathrm{~N}_{5} \mathrm{O}_{8} \mathrm{P}_{2}$ 516.1413, found 516.1403; HPLC $13.5 \mathrm{~min}$ (99\%) in solvent system A, 16.9 min (99\%) in solvent system B.

(1'R,2' S,4'S,5' S)-4-(2-Hex-1-enyl-6-methylaminopurin-9-yl)-1-[(phosphato)methyl]-2(phosphato)bicyclo[3.1.0]-hexane (18)

The 2-hexynyl bisphosphate derivative 18 ( $4.0 \mathrm{mg}, 73 \%)$ was prepared by the same method as above for 11, except the 2-hexynyl bis(di-tert-butyl phosphate) derivative $\mathbf{5 0}(7.0 \mathrm{mg}$, $9.46 \mu \mathrm{mol})$ was used as the starting material: ${ }^{1} \mathrm{H}$ NMR $\left(\mathrm{D}_{2} \mathrm{O}\right) \delta 8.46(\mathrm{~s}, 1 \mathrm{H}), 5.16(\mathrm{~m}, 1 \mathrm{H})$, 4.97 (d, $1 \mathrm{H}, J=6.3 \mathrm{~Hz}), 4.56$ (dd, $1 \mathrm{H}, J=4.7,11.3 \mathrm{~Hz}), 3.70$ (dd, $1 \mathrm{H}, J=6.3,11.3 \mathrm{~Hz}$ ), $3.07(\mathrm{bs}, 3 \mathrm{H}), 2.50(\mathrm{t}, 2 \mathrm{H}, J=7.1 \mathrm{~Hz}), 2.24(\mathrm{dd}, 1 \mathrm{H}, J=7.4,14.6 \mathrm{~Hz}), 1.91-2.05(\mathrm{~m}, 2 \mathrm{H})$, $1.42-1.71(\mathrm{~m}, 4 \mathrm{H}), 1.23(\mathrm{dd}, 1 \mathrm{H}, J=4.1,5.8 \mathrm{~Hz}), 1.03(\mathrm{dd}, 1 \mathrm{H}, J=6.1,8.2 \mathrm{~Hz}), 0.95(\mathrm{t}, 3 \mathrm{H}$, $J=7.2 \mathrm{~Hz}$ ); ${ }^{31} \mathrm{P}$ NMR $\left(\mathrm{D}_{2} \mathrm{O}\right) 0.777(\mathrm{~s}), 0.375(\mathrm{~s})$; HRMS (negative-ion FAB) calcd for $\mathrm{C}_{19} \mathrm{H}_{26} \mathrm{~N}_{5} \mathrm{O}_{8} \mathrm{P}_{2}$ 514.1257, found 514.1234; HPLC 12.4 min (98\%) in solvent system A, 12.3 min (99\%) in solvent system B.

\section{General (Phosphorylation) Procedure: Synthesis of $(M)$-Methanocarbaadenosine Derivatives (21-57). (1'R,2'S,-4'S,5'S)-4-(2-Amino-6-chloro-9H-purin-9-yl)-1- (benzyloxymethyl)-2-benzyloxybicyclo[3.1.0]hexane (21)}

To a solution of triphenylphosphine $(0.20 \mathrm{~g}, 0.76 \mathrm{mmol})$ in anhydrous tetrehydrofuran (THF, $1.0 \mathrm{~mL}$ ) was added dropwise diisopropyl azodicarboxylate (DIAD, $0.15 \mathrm{~mL}, 0.76$ $\mathrm{mmol})$ at $-20{ }^{\circ} \mathrm{C}$ with stirring for $0.5 \mathrm{~h}$. Compound 19 (76 mg, $0.23 \mathrm{mmol}$ ) and 2-amino-6chloropurine 20 ( $92 \mathrm{mg}, 0.54 \mathrm{mmol})$ in THF $(5.0 \mathrm{~mL})$ were added to the reaction mixture and it stirred for $18.5 \mathrm{~h}$ at room temperature. The solvent was removed under vacuum, and the residue obtained was purified by using flash chromatography with $1 / 1$ petroleum ether/ ethyl acetate to furnish $21(103 \mathrm{mg}, 92 \%):{ }^{1} \mathrm{H}$ NMR $\left(\mathrm{CDCl}_{3}\right) \delta 8.58(\mathrm{~s}, 1 \mathrm{H}), 7.40-7.21(\mathrm{~m}$, $10 \mathrm{H}), 5.01(\mathrm{bs}, 1 \mathrm{H}), 4.97(\mathrm{~d}, 1 \mathrm{H}, J=6.6 \mathrm{~Hz}), 4.66(\mathrm{t}, 1 \mathrm{H}, J=8.25 \mathrm{~Hz}), 4.54(\mathrm{~s}, 2 \mathrm{H}), 4.45(\mathrm{~d}$, $1 \mathrm{H}, J=11.7 \mathrm{~Hz}), 4.38(\mathrm{~d}, 1 \mathrm{H}, J=11.7 \mathrm{~Hz}), 4.09(\mathrm{~d}, 1 \mathrm{H}, J=9.8 \mathrm{~Hz}), 3.14(\mathrm{~d}, 1 \mathrm{H}, J=9.8$ $\mathrm{Hz}), 2.09-2.00(\mathrm{~m}, 1 \mathrm{H}), 1.85-1.74(\mathrm{~m}, 1 \mathrm{H}), 1.59-1.54(\mathrm{~m}, 1 \mathrm{H}), 1.11-1.06(\mathrm{~m}, 1 \mathrm{H}), 0.81-$ $0.75(\mathrm{~m}, 1 \mathrm{H}) ; \mathrm{MS}(\mathrm{m} / \mathrm{e})$ (positive-FAB) 476, 478 (peak height ratio $=3: 1)\left(\mathrm{M}^{+}+1\right)$.

(1'R,2'S,4'S,5'S)-4-(2-Amino-6-chloro-9H-purin-9-yl)-1-(hydroxymethyl)-2hydroxybicyclo[3.1.0]hexane (22)

Compound 21 (169 mg, $0.353 \mathrm{mmol}$ ) was dissolved in $\mathrm{CH}_{2} \mathrm{Cl}_{2}(5.0 \mathrm{~mL})$ and treated with $\mathrm{BCl}_{3}\left(1 \mathrm{M}\right.$ in $\left.\mathrm{CH}_{2} \mathrm{Cl}_{2}, 1.50 \mathrm{~mL}\right)$ for $1 \mathrm{~h}$ at $-40{ }^{\circ} \mathrm{C}$ under argon. $i-\mathrm{PrOH}(0.40 \mathrm{~mL})$ was added to the reaction mixture and it was warmed to room temperature. The solvent was evaporated, and the crude product was purified by flash column chromatography with $\mathrm{AcOEt} / \mathrm{i}-\mathrm{PrOH}$ $(1 / 1)$ to yield 22 as a white solid $(72 \mathrm{mg}, 69 \%):{ }^{1} \mathrm{H}$ NMR $\left(\mathrm{CD}_{3} \mathrm{OD}\right) \delta 8.54(\mathrm{~s}, 1 \mathrm{H}), 4.94(\mathrm{~d}$, $1 \mathrm{H}, J=6.6 \mathrm{~Hz}), 4.26(\mathrm{~d}, 1 \mathrm{H}, J=11.7 \mathrm{~Hz}), 4.03(\mathrm{~s}, 1 \mathrm{H}), 3.33(\mathrm{~d}, 1 \mathrm{H}, J=11.7 \mathrm{~Hz}), 2.09-1.98$ (m, 1H), 1.84-1.73 (m, 1H), 1.67-1.62 (m, 1H), 1.04-0.99 (m, 1H), 0.79-0.74 (m, 1H); MS $(\mathrm{m} / \mathrm{e})\left(\right.$ negative-FAB) 294, $296($ peak height ratio $=3: 1)\left(\mathrm{M}^{+}-1\right)$.

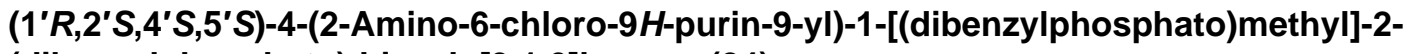
(dibenzylphosphato)-bicyclo[3.1.0]hexane (24)

To a stirred solution of $22(56 \mathrm{mg}, 0.190 \mathrm{mmol})$ and $1 H$-tetrazole $(130 \mathrm{mg}, 1.86 \mathrm{mmol})$ in $3.0 \mathrm{~mL}$ of anhydrous THF was added dibenzyl diisopropylphosphoramidite $(\mathbf{2 3}, 0.30 \mathrm{~mL}$, $0.89 \mathrm{mmol}$ ), and the mixture was stirred for $4.5 \mathrm{~h}$ at room temperature. The reaction mixture was cooled to $-78{ }^{\circ} \mathrm{C}$ and treated with a solution of $m$-chloroperbenzoic acid ( $m$-CPBA, $70 \%$ max, $350 \mathrm{mg})$ in $\mathrm{CH}_{2} \mathrm{Cl}_{2}(5.0 \mathrm{~mL})$. The resulting mixture was warmed to room 
temperature, and the solvent was removed under reduced pressure. The residue obtained was purified by flash column chromatography $\left(1 / 1=\mathrm{AcOEt} / \mathrm{CH}_{2} \mathrm{Cl}_{2}\right)$, which furnished 24 (52 $\mathrm{mg}, 35 \%):{ }^{1} \mathrm{H}$ NMR $\left(\mathrm{CDCl}_{3}\right) \delta 7.82(\mathrm{~s}, 1 \mathrm{H}), 7.33-7.25(\mathrm{~m}, 20 \mathrm{H}), 5.41(\mathrm{dd}, 1 \mathrm{H}, J=7.8,14.1$ $\mathrm{Hz}), 5.27(\mathrm{bs}, 2 \mathrm{H}), 5.05-4.91(\mathrm{~m}, 8 \mathrm{H}), 4.74(\mathrm{~d}, 1 \mathrm{H}, J=6.9 \mathrm{~Hz}), 4.54(\mathrm{dd}, 1 \mathrm{H}, J=5.7,11.1$ $\mathrm{Hz}), 3.94(\mathrm{dd}, 1 \mathrm{H}, J=6.0,11.1 \mathrm{~Hz}), 2.14-2.04(\mathrm{~m}, 1 \mathrm{H}), 1.98-1.87(\mathrm{~m}, 1 \mathrm{H}), 1.62-1.52(\mathrm{~m}$, $1 \mathrm{H}), 1.00-0.93(\mathrm{~m}, 1 \mathrm{H}), 0.87-0.80(\mathrm{~m}, 1 \mathrm{H})$; MS ( $\mathrm{m} / \mathrm{e})$ (positive-FAB) 816, 818 (peak height ratio $=3: 1)\left(\mathrm{M}^{+}+1\right)$.

(1'R,2' S,4'S,5'S)-4-(6-Chloro-2-iodo-9H-purin-9-yl)-1-[(dibenzylphosphato)methyl]-2(dibenzylphosphato)-bicyclo[3.1.0]hexane (25)

To a solution of $24(62.1 \mathrm{mg}, 0.0761 \mathrm{mmol})$ in acetonitrile $(0.50 \mathrm{~mL})$ were added diiodomethane $(2.0 \mathrm{~mL})$ and tert-butyl nitrite $(0.10 \mathrm{~mL}, 1.11 \mathrm{mmol})$ were added, and oxygen was purged by $\mathrm{N}_{2}$ bubbling. The tube was sealed and stirred at $85{ }^{\circ} \mathrm{C}$ for $3.0 \mathrm{~h}$. Diiodomethane was removed upon passage though a short column (silica gel, eluting with $\mathrm{CHCl}_{3}$, then AcOEt). The residue obtained was purified by preparative thin-layer chromatography (AcOEt), which furnished $25(25.8 \mathrm{mg}, 37 \%):{ }^{1} \mathrm{H} \mathrm{NMR}\left(\mathrm{CDCl}_{3}\right) \delta 8.19$ (s, $1 \mathrm{H}), 7.36-7.25(\mathrm{~m}, 20 \mathrm{H}), 5.29(\mathrm{q}, 1 \mathrm{H}, J=6.9 \mathrm{~Hz}), 5.10-4.92(\mathrm{~m}, 9 \mathrm{H}), 4.61(\mathrm{dd}, 1 \mathrm{H}, J=6.3$, $12.0 \mathrm{~Hz}), 3.84(\mathrm{dd}, 1 \mathrm{H}, J=6.6,12.0 \mathrm{~Hz}), 2.05-1.88(\mathrm{~m}, 2 \mathrm{H}), 1.62-1.52(\mathrm{~m}, 1 \mathrm{H}), 1.02(\mathrm{~m}$, $1 \mathrm{H}), 0.95-0.84(\mathrm{~m}, 1 \mathrm{H})$; MS (m/e) (positive-FAB) 928, $930($ peak height ratio $=3: 1)\left(\mathrm{M}^{+}+\right.$ $1)$.

(1'R,2'S,4'S,5'S)-4-(6-Chloro-2-methylthio-9H-purin-9-yl)-1-[(dibenzylphosphato)methyl]-2(dibenzylphosphato)-bicyclo[3.1.0]hexane (26)

To a solution of $24(4.5 \mathrm{mg}, 0.0056 \mathrm{mmol})$ in $\mathrm{MeCN}(0.25 \mathrm{~mL})$ were added dimethyl disulfide $(0.15 \mathrm{~mL}, 1.26 \mathrm{mmol})$ and tert-butylnitrite $(0.050 \mathrm{~mL}, 0.56 \mathrm{mmol})$, and oxygen was purged by nitrogen bubbling. The tube was sealed and stirred at $70{ }^{\circ} \mathrm{C}$ for $5.5 \mathrm{~h}$. The solvent was removed under reduced pressure. The residue obtained was purified by preparative thin-layer chromatography $\left(2 / 1=\mathrm{AcOEt} / \mathrm{CH}_{2} \mathrm{Cl}_{2}\right)$, which furnished $\mathbf{2 6}(3.0 \mathrm{mg}$, 64\%): ${ }^{1} \mathrm{H}$ NMR $\left(\mathrm{CDCl}_{3}\right) \delta 8.15(\mathrm{~s}, 1 \mathrm{H}), 7.33-7.25(\mathrm{~m}, 20 \mathrm{H}), 5.30(\mathrm{dd}, 1 \mathrm{H}, J=7.8,14.7$ $\mathrm{Hz}), 5.07-4.91(\mathrm{~m}, 9 \mathrm{H}), 4.62(\mathrm{dd}, 1 \mathrm{H}, J=6.0,11.5 \mathrm{~Hz}), 3.74(\mathrm{dd}, 1 \mathrm{H}, J=6.6,11.5 \mathrm{~Hz}), 2.61$ (s, 3H), 2.14-2.04 (m, 1H), 1.98-1.87 (m, 1H), 1.63-1.56 (m, 1H), 1.07-1.03 (m, 1H), 0.88$0.81(\mathrm{~m}, 1 \mathrm{H})$; MS $(\mathrm{m} / \mathrm{e})$ (positive-FAB) $847,849($ peak height ratio $=3: 1)\left(\mathrm{M}^{+}+1\right)$.

(1'R,2' S,4'S,5'S)-4-(6-Chloro-2-methylseleno-9H-purin-9-yl)-1[(dibenzylphosphato)methyl]-2-(dibenzylphosphato)bicyclo[3.1.0]hexane (27)

To a solution of $24(16.0 \mathrm{mg}, 0.0196 \mathrm{mmol})$ in $\mathrm{MeCN}(0.30 \mathrm{~mL})$ were added dimethyldiselenide $(0.10 \mathrm{~mL}, 1.06 \mathrm{mmol})$ and tert-butyl nitrite $(0.100 \mathrm{~mL}, 1.11 \mathrm{mmol})$, and oxygen was purged by nitrogen bubbling. The tube was sealed and stirred at $65^{\circ} \mathrm{C}$ for $20 \mathrm{~h}$. The solvent was removed under reduced pressure. The residue obtained was purified by preparative thin-layer chromatography $\left(1 / 1=\mathrm{AcOEt} / \mathrm{CH}_{2} \mathrm{Cl}_{2}\right)$, which furnished $27(6.7 \mathrm{mg}$, $38 \%):{ }^{1} \mathrm{H}$ NMR $\left(\mathrm{CDCl}_{3}\right) \delta 8.16(\mathrm{~s}, 1 \mathrm{H}), 7.40-7.25(\mathrm{~m}, 20 \mathrm{H}), 5.28(\mathrm{dd}, 1 \mathrm{H}, J=8.4,14.4$ $\mathrm{Hz}), 5.10-4.90(\mathrm{~m}, 9 \mathrm{H}), 4.62(\mathrm{dd}, 1 \mathrm{H}, J=6.0,11.4 \mathrm{~Hz}), 3.74(\mathrm{dd}, 1 \mathrm{H}, J=6.6,14.4 \mathrm{~Hz}), 2.53$ (s, 3H), 2.15-2.00 (m, 1H), 2.00-1.85 (m, 1H), 1.75-1.65 (m, 1H), 1.45-1.35 (m, 1H), 1.10$1.00(\mathrm{~m}, 1 \mathrm{H}) ; \mathrm{MS}(\mathrm{m} / \mathrm{e})$ (positive-FAB) 895, 897 (peak height ratio $=3: 1)\left(\mathrm{M}^{+}+1\right)$.

\section{(1'R,2' S,4'S,5'S)-4-(6-Methylamino-2-methylthio-9H-purin-9-yl)-1-[(dibenzylphosphato)- methyl]-2-(dibenzylphosphato)bicyclo[3.1.0]hexane (28)}

Compound 26 ( $3.0 \mathrm{mg}, 0.0035 \mathrm{mmol})$ was dissolved in $2.0 \mathrm{M} \mathrm{MeNH}_{2}$ in THF $(0.50 \mathrm{~mL})$ and stirred for $2.5 \mathrm{~h}$ at room temperature. The solvent was removed under reduced pressure. The residue obtained was purified by preparative thin-layer chromatography (AcOEt), which furnished $28(2.7 \mathrm{mg}, 91 \%):{ }^{1} \mathrm{H}$ NMR $\left(\mathrm{CDCl}_{3}\right) \delta 7.77(\mathrm{~s}, 1 \mathrm{H}), 7.30-7.25(\mathrm{~m}, 20 \mathrm{H}), 5.72(\mathrm{bs}$, 
$1 \mathrm{H}), 5.38(\mathrm{dd}, 1 \mathrm{H}, J=7.5,14.1 \mathrm{~Hz}), 5.03-4.91(\mathrm{~m}, 9 \mathrm{H}), 4.59(\mathrm{dd}, 1 \mathrm{H}, J=6.3,11.4 \mathrm{~Hz})$, 3.78 (dd, $1 \mathrm{H}, J=5.1,11.4 \mathrm{~Hz}$ ), 3.19 (bs, 3H), 2.57 (s, 3H), 2.19-2.10 (m, 1H), 1.96-1.82 $(\mathrm{m}, 1 \mathrm{H}), 1.60-1.55(\mathrm{~m}, 1 \mathrm{H}), 1.04-1.00(\mathrm{~m}, 1 \mathrm{H}), 0.88-0.78(\mathrm{~m}, 1 \mathrm{H})$; MS $(\mathrm{m} / \mathrm{e})$ (positiveFAB) $842\left(M^{+}+1\right)$.

\section{(1'R,2'S,4'S,5'S)-4-(6-Chloro-2-iodo-9H-purin-9-yl)-1-[(phosphato)methyl]-2- (phosphato)bicyclo[3.1.0]-hexane Tetraammonium Salt (29)}

To a solution of $25(13.6 \mathrm{mg}, 0.015 \mathrm{mmol})$ in $\mathrm{CH}_{2} \mathrm{Cl}_{2}(0.80 \mathrm{~mL})$ was added $1.0 \mathrm{M} \mathrm{BCl}_{3}$ in $\mathrm{CH}_{2} \mathrm{Cl}_{2}(0.80 \mathrm{~mL})$ and the mixture stirred for $24 \mathrm{~h}$ at $5{ }^{\circ} \mathrm{C}$. The reaction was quenched upon addition of $3.0 \mathrm{~mL}$ of triethylammonium bicarbonate buffer $(1.0 \mathrm{M})$. The mixture was subsequently frozen and lyophilized. Purification of the residue obtained was performed on an ion-exchange column packed with Sephadex-DEAE A-25 resin. A linear gradient (0.01$0.5 \mathrm{M}$ ) of $0.5 \mathrm{M}$ ammonium bicarbonate was applied as the mobile phase, and UV and HPLC were used to monitor the elution, which furnished $29(5.56 \mathrm{mg}, 60 \%):{ }^{1} \mathrm{H} \mathrm{NMR}$ $\left(\mathrm{D}_{2} \mathrm{O}\right) \delta 8.83(\mathrm{~s}, 1 \mathrm{H}), 5.30-5.20(\mathrm{~m}, 1 \mathrm{H}), 5.16(\mathrm{~d}, 1 \mathrm{H}, J=6.3 \mathrm{~Hz}), 4.60-4.50(\mathrm{~m}, 1 \mathrm{H}), 3.75-$ $3.65(\mathrm{~m}, 1 \mathrm{H}), 2.40-2.20(\mathrm{~m}, 1 \mathrm{H}), 2.10-1.95(\mathrm{~m}, 1 \mathrm{H}), 1.95-1.90(\mathrm{~m}, 1 \mathrm{H}), 1.25-1.20(\mathrm{~m}, 1 \mathrm{H})$, 1.05-1.00 (m, 1H); ${ }^{31} \mathrm{P}$ NMR $\left(\mathrm{D}_{2} \mathrm{O}\right) \delta 2.02,1.40\left(2 \mathrm{~s}, 3^{\prime}-\mathrm{P}, 5^{\prime}-\mathrm{P}\right) ; \mathrm{MS}(\mathrm{m} / \mathrm{e})$ (negative-FAB) $565,567$ (peak height ratio $=3: 1)\left(\mathrm{M}^{+}-1\right)$; HPLC $9.8 \mathrm{~min}(98 \%)$ in solvent system A, 16.0 $\min (98 \%)$ in solvent system B.

\section{(1'R,2' S,4'S,5' S)-4-(6-Chloro-2-methylseleno-9H-purin-9-yl)-1-[(phosphato)methyl]-2-} (phosphato)bicyclo[3.1.0]-hexane Tetraammonium Salt (30)

To a solution of $27(6.7 \mathrm{mg}, 0.0075 \mathrm{mmol})$ in $\mathrm{CH}_{2} \mathrm{Cl}_{2}(0.50 \mathrm{~mL})$ was added $1.0 \mathrm{M} \mathrm{BCl}_{3}$ in $\mathrm{CH}_{2} \mathrm{Cl}_{2}(0.80 \mathrm{~mL})$ and the mixture stirred for $2 \mathrm{~d}$ at $5{ }^{\circ} \mathrm{C}$. The reaction was quenched upon addition of $5.0 \mathrm{~mL}$ of triethylammonium bicarbonate buffer $(1.0 \mathrm{M})$. The mixture was subsequently frozen and lyophilized. Purification of the obtained residue was performed on an ion-exchange column packed with Sephadex-DEAE A-25 resin, a linear gradient (0.01$0.5 \mathrm{M}$ ) of $0.5 \mathrm{M}$ ammonium bicarbonate was applied as the mobile phase, and UV and HPLC were used to monitor the elution, which furnished 30 (1.28 mg, 28\%): ${ }^{1} \mathrm{H}$ NMR $\left(\mathrm{D}_{2} \mathrm{O}\right) \delta 8.78(\mathrm{~s}, 1 \mathrm{H}), 5.35-5.22(\mathrm{~m}, 2 \mathrm{H}), 4.60-4.50(\mathrm{~m}, 1 \mathrm{H}), 3.70-3.65(\mathrm{~m}, 1 \mathrm{H}), 2.61(\mathrm{~s}$, $3 \mathrm{H}), 2.45-2.30(\mathrm{~m}, 1 \mathrm{H}), 2.15-1.95(\mathrm{~m}, 1 \mathrm{H}), 1.95-1.85(\mathrm{~m}, 1 \mathrm{H}), 1.25-1.18(\mathrm{~m}, 1 \mathrm{H}), 1.05-$ $0.95(\mathrm{~m}, 1 \mathrm{H}) ;{ }^{31} \mathrm{P}$ NMR $\left(\mathrm{D}_{2} \mathrm{O}\right) \delta 1.67,1.09\left(2 \mathrm{~s}, 3^{\prime}-\mathrm{P}, 5^{\prime}-\mathrm{P}\right)$; MS $(\mathrm{m} / \mathrm{e})$ (negative-FAB) 533, 535 (peak height ratio $=3: 1)\left(\mathrm{M}^{+}-1\right)$, HRMS (negative-FAB) calcd for $\mathrm{C}_{13} \mathrm{H}_{16} \mathrm{~N}_{4} \mathrm{O}_{8} \mathrm{P}_{2} \mathrm{Se}$ 532.9293, found 532.9295; HPLC $11.0 \mathrm{~min}(99 \%)$ in solvent system A, $15.5 \mathrm{~min}(99 \%)$ in solvent system B.

\section{(1'R,2'S,4'R,5'S)-Acetic Acid 4-Hydroxy-5-hydroxymethylbicyclo[3.1.0]hex-2-yl Ester (32)}

A mixture of dibenzyl alcohol $19(137 \mathrm{mg}, 0.422 \mathrm{mmol})$, acetic anhydride (140.4 mg, 1.38 $\mathrm{mmol}$ ), triethylamine (436 mg, $4.3 \mathrm{mmol}), 4$-(dimethylamino)pyridine (10 mg, $0.2 \mathrm{mmol})$, and dichloromethane $(5 \mathrm{~mL})$ was stirred at room temperature for $4 \mathrm{~h}$. The resulting mixture was partitioned between ethyl acetate $(50 \mathrm{~mL})$ and water/brine $(1 / 1,20 \mathrm{~mL})$. The organic layer was washed with saturated aqueous sodium bicarbonate $(10 \mathrm{~mL})$ and brine $(10 \mathrm{~mL})$, dried over sodium sulfate, filtered, and concentrated in vacuo. The residue was used in the next reaction without further purification. The dibenzyl acetate $\mathbf{3 1}$ (crude $164 \mathrm{mg}$ ) was dissolved in methanol $(5 \mathrm{~mL})$. Five percent $\mathrm{Pd} / \mathrm{C}(150 \mathrm{mg})$ was added. The reaction flask was applied to a vacuum and filled with hydrogen several times. The reaction mixture was stirred for $4 \mathrm{~h}$ at room temperature under a hydrogen balloon. The resulting mixture was filtrated through a pad of Celite and washed with methanol $(10 \mathrm{~mL} \times 3)$. The residue was purified by flash column chromatography (chloroform/methanol $=10 / 1$ ) to give a diol 32 (76 mg, 97\% for two steps yield): ${ }^{1} \mathrm{H}$ NMR $\left(\mathrm{CDCl}_{3}\right) \delta 5.13(\mathrm{~m}, 1 \mathrm{H}), 4.45(\mathrm{t}, 1 \mathrm{H}, J=8.2$ $\mathrm{Hz}), 3.96(\mathrm{~d}, 1 \mathrm{H}, J=11.8 \mathrm{~Hz}), 3.24(\mathrm{~d}, 1 \mathrm{H}, J=11.8 \mathrm{~Hz}), 2.33(\mathrm{dt}, 1 \mathrm{H}, J=8.0,13.2 \mathrm{~Hz})$, 
$2.01(\mathrm{~s}, 3 \mathrm{H}), 1.66(\mathrm{~m}, 1 \mathrm{H}), 1.27$ (dt, $1 \mathrm{H}, J=8.8,13.5 \mathrm{~Hz}), 1.09$ (dd, $1 \mathrm{H}, J=3.8,5.5 \mathrm{~Hz})$,

$0.55(\mathrm{dd}, 1 \mathrm{H}, J=5.5,8.0 \mathrm{~Hz})$.

(1'R,2' $\left.S, 4^{\prime} R, 5^{\prime} S\right)$-Acetic Acid 4-(Di-tert-butoxyphosphoryloxy)-5-(di-tertbutoxyphosphoryloxymethyl)-bicyclo[3.1.0] hex-2-yl Ester (33)

To a stirred suspension of diol $32(25 \mathrm{mg}, 0.134 \mathrm{mmol})$ and diethyl di-tertbutylphosphoramidite $(100.5 \mathrm{mg}, 0.402 \mathrm{mmol})$ in anhydrous tetrahydrofuran $(4 \mathrm{~mL})$ at room temperature was added solid tetrazole $(94 \mathrm{mg}, 1.34 \mathrm{mmol})$ in one pot. The reaction mixture was stirred at room temperature for $1 \mathrm{~h}$ and then cooled to $-78{ }^{\circ} \mathrm{C}$. To this cooled reaction mixture was added solid $m$-CPBA $(57-85 \%$, calculated by $57 \%, 240 \mathrm{mg}$ ), and the resulting mixture was stirred at $-78{ }^{\circ} \mathrm{C}$ for $20 \mathrm{~min}$ and at room temperature for $10 \mathrm{~min}$. After removal of tetrahydrofuran in vacuo, the residue was directly purified by flash column chromatography $\left(\mathrm{CHCl}_{3} / \mathrm{MeOH}=10 / 1\right)$ to give $\mathbf{3 3}(71 \mathrm{mg}, 93 \%):{ }^{1} \mathrm{H} \mathrm{NMR}\left(\mathrm{CDCl}_{3}\right) \delta 4.87$ $(\mathrm{dd}, 1 \mathrm{H}, J=8.0,14.6 \mathrm{~Hz}), 4.41(\mathrm{~m}, 1 \mathrm{H}), 4.40(\mathrm{dd}, 1 \mathrm{H}, J=7.7,11.0 \mathrm{~Hz}), 3.69(\mathrm{dd}, 1 \mathrm{H}, J=$ 6.9, $11.0 \mathrm{~Hz}), 2.46(\mathrm{dt}, 1 \mathrm{H}, J=7.7,13.5 \mathrm{~Hz}), 1.78(\mathrm{~m}, 1 \mathrm{H}), 1.485(\mathrm{~s}, 9 \mathrm{H}), 1.478(\mathrm{~s}, 9 \mathrm{H})$, $1.469(\mathrm{~s}, 9 \mathrm{H}), 1.457(\mathrm{~s}, 9 \mathrm{H}), 1.39(\mathrm{~m}, 1 \mathrm{H}), 1.25(\mathrm{dd}, 1 \mathrm{H}, J=5.0,5.2 \mathrm{~Hz}), 0.67(\mathrm{dd}, 1 \mathrm{H}, J=$ $6.3,7.4 \mathrm{~Hz})$.

\section{(1'R,2' S,4'R,5'S)-Phosphoric Acid Di-tert-butyl Ester 1-(Di-tert- butoxyphosphoryloxymethyl)-4-hydroxybicyclo[3.1.0]hex-2-yl Ester (34)}

Acetate 33 (70 mg, $0.122 \mathrm{mmol}$ ) was dissolved in methanol ( $3 \mathrm{~mL})$, and then solid potassium carbonate $(20 \mathrm{mg}, 0.145 \mathrm{mmol})$ was added. After the reaction mixture was stirred for $2 \mathrm{~h}$, methanol was removed in vacuo and the residue was purified by flash column chromatography $\left(\mathrm{CHCl}_{3} / \mathrm{MeOH}=30 / 1\right)$ to produce the bisphosphate alcohol $34(51 \mathrm{mg}$, 79\%): ${ }^{1} \mathrm{H}$ NMR $\left(\mathrm{CDCl}_{3}\right) \delta 5.13(\mathrm{~m}, 1 \mathrm{H}), 4.45(\mathrm{t}, 1 \mathrm{H}, J=8.2 \mathrm{~Hz}), 3.96(\mathrm{~d}, 1 \mathrm{H}, J=11.8 \mathrm{~Hz})$, $3.24(\mathrm{~d}, 1 \mathrm{H}, J=11.8 \mathrm{~Hz}), 2.33(\mathrm{dt}, 1 \mathrm{H}, J=8.0,13.2 \mathrm{~Hz}), 2.01(\mathrm{~s}, 3 \mathrm{H}), 1.66(\mathrm{~m}, 1 \mathrm{H}), 1.27$ $(\mathrm{dt}, 1 \mathrm{H}, J=8.8,13.5 \mathrm{~Hz}), 1.09(\mathrm{dd}, 1 \mathrm{H}, J=3.8,5.5 \mathrm{~Hz}), 0.55(\mathrm{dd}, 1 \mathrm{H}, J=5.5,8.0 \mathrm{~Hz}) ; \mathrm{MS}$ $(\mathrm{m} / \mathrm{e})$ (positive-FAB) $529.35\left(\mathrm{M}^{+}+1\right), 551.31\left(\mathrm{M}^{+}+\mathrm{Na}+1\right)$.

\section{2-Bromo-6-chloro-9H-purine (35)}

To a stirred solution of $\mathbf{2 0}(0.35 \mathrm{~g}, 2 \mathrm{mmol})$ in $\mathrm{CH}_{2} \mathrm{Br}_{2}(5 \mathrm{~mL})$ was added a solution of $\mathrm{SbBr}_{3}$ in $\mathrm{CH}_{2} \mathrm{Br}_{2}(5 \mathrm{~mL})$ at $-10{ }^{\circ} \mathrm{C}$. This solution was stirred at this temperature for $10 \mathrm{~min}$, and tert-butyl nitrite $(4.5 \mathrm{~mL})$ was added. The reaction mixture was stirred for $2.5 \mathrm{~h}$ at -10 ${ }^{\circ} \mathrm{C}$ and then was poured into a stirred mixture of $2.4 \mathrm{~g}$ of $\mathrm{NaHCO}_{3}$ in $100 \mathrm{~mL}$ of water and crushed ice. This mixture was filtered, and the filtrate was extracted with $\mathrm{CHCl}_{3}$ and dried over $\mathrm{Na}_{2} \mathrm{SO}_{4}$. After removal of the solvent, the residue was purified by flash chromatography $\left(\mathrm{MeOH} / \mathrm{CHCl}_{3}=1 / 10\right)$ to provide $35(0.404 \mathrm{~g}, 87 \%):{ }^{1} \mathrm{H}$ NMR (DMSO- $\left.d_{6}\right)$ $\delta 8.72(\mathrm{~s}, 1 \mathrm{H}) ; \mathrm{MS}(\mathrm{m} / \mathrm{e})$ (positive-FAB) $233\left(\mathrm{M}^{+}+\mathrm{H}\right)$.

\section{6-Chloro-2-fluoro-9H-purine (36)}

Compound 20 (100 mg, $0.572 \mathrm{mmol}$ ) was added to 60\% HF-pyridine (which was prepared from $1.5 \mathrm{~g}$ of $70 \% \mathrm{HF}$-pyridine diluted with $0.25 \mathrm{~g}$ of pyridine) at $-50{ }^{\circ} \mathrm{C}$ with stirring. The temperature was allowed to rise from $-30{ }^{\circ} \mathrm{C}$, and $0.1 \mathrm{~mL}$ of tert-butyl nitrite $(0.1 \mathrm{~mL})$ was added dropwise. Stirring was continued for $10 \mathrm{~min}$, and the reaction mixture was poured into ice water. The aqueous layer was extracted with $\mathrm{CHCl}_{3}$ and ethyl acetate. The combined organic layer was washed with $\mathrm{H}_{2} \mathrm{O}$, dried over $\mathrm{Na}_{2} \mathrm{SO}_{4}$, and filtered, and the filtrate was evaporated. The given residue was purified on a flash column chromatography $\left(\mathrm{MeOH} / \mathrm{CHCl}_{3}=1 / 10\right)$ to give $\mathbf{3 6}(90 \mathrm{mg}, 91 \%)$ as a white solid: ${ }^{1} \mathrm{H} \mathrm{NMR}\left(\mathrm{CD}_{3} \mathrm{OD}\right) \delta 8.5$ (s, 1H); MS (m/e) (positive-FAB) $173\left(\mathrm{M}^{+}+\mathrm{H}\right)$. 


\section{2-Fluoro-6-methylamino-9H-purine (37)}

The mixture of $36(56 \mathrm{mg}, 0.324 \mathrm{mmol})$ in $\mathrm{CH}_{3} \mathrm{NH}_{2}(2.0 \mathrm{M}$ in THF, $3 \mathrm{~mL}$ ) was stirred at room temperature overnight. After removal of the solvent, the residue was purified by preparative thin-layer chromatography $\left(\mathrm{MeOH} / \mathrm{CHCl}^{3}=1 / 10\right)$ to yield $37(43 \mathrm{mg}, 80 \%):{ }^{1} \mathrm{H}$ NMR (DMSO- $\left.d_{6}\right) \delta 8.12(\mathrm{br}, 1 \mathrm{H}), 8.06(\mathrm{~s}, 1 \mathrm{H}), 3.30(\mathrm{~s}, 1 \mathrm{H}), 2.91(\mathrm{~s}, 3 \mathrm{H}) ; \mathrm{MS}(\mathrm{m} / \mathrm{e})$ (positive-FAB) $168\left(\mathrm{M}^{+}+\mathrm{H}\right)$.

\section{2-Bromo-6-methylamino-9H-purine (38)}

The mixture of 35 (130 mg, $0.557 \mathrm{mmol})$ in $\mathrm{CH}_{3} \mathrm{NH}_{2}\left(40 \%\right.$ in $\left.\mathrm{H}_{2} \mathrm{O}, 2 \mathrm{~mL}\right)$ was heated to 70 ${ }^{\circ} \mathrm{C}$ and stirred at this temperature for $6 \mathrm{~h}$. The reaction mixture was cooled to room temperature, and the formed white precipitate was filtered and washed with a small amount of water/MeOH. The precipitate was dried in a vacuum to give $\mathbf{3 8}(118 \mathrm{mg}, 93 \%):{ }^{1} \mathrm{H}$ NMR (DMSO- $\left.d_{6}\right) \delta 8.08(\mathrm{~s}, 1 \mathrm{H}), 8.06(\mathrm{bs}, 1 \mathrm{H}), 3.30(\mathrm{~s}, 1 \mathrm{H}), 2.91(\mathrm{~s}, 3 \mathrm{H})$; MS (m/e) (positiveFAB) $228\left(\mathrm{M}^{+}+\mathrm{H}\right)$.

(1'R,2'S,4'S,5'S)-4-(2-Fluoro-6-methylamino-9H-purin-9-yl)-1-(di-tertbutoxyphosphoryloxymethyl)bicyclo[3.1.0]-hex-2-yl-phosphoric Acid Di-tert-butyl Ester (44)

To an ice-cold solution of triphenylphosphine $(23.6 \mathrm{mg}, 0.09 \mathrm{mmol})$ in dry THF $(0.5 \mathrm{~mL})$ was added DIAD $(18.7 \mu \mathrm{L}, 0.09 \mathrm{mmol})$ dropwise under a nitrogen atmosphere, and the mixture was stirred for $20 \mathrm{~min}$ until the solution turned red. This mixture was added dropwise to a cold, stirred mixture of $\mathbf{3 4}(14.4 \mathrm{mg}, 0.027 \mathrm{mmol})$ and $\mathbf{3 7}$ (15.03 $\mathrm{mg}, 0.09$ $\mathrm{mmol})$ under a nitrogen atmosphere. The reaction mixture was stirred in an ice bath for 30 min and then allowed to warm to room temperature, and stirring continued for $12 \mathrm{~h}$. Solvent was removed by nitrogen purge, and the residue was purified by preparative thin-layer chromatography $\left(\mathrm{MeOH} / \mathrm{CHCl}_{3}=1 / 20\right)$ to produce $44(8.61 \mathrm{mg}, 47 \%)$ as a thick liquid: ${ }^{1} \mathrm{H}$ NMR $\left(\mathrm{CDCl}_{3}\right) \delta 8.08(\mathrm{~s}, 1 \mathrm{H}), 6.18(\mathrm{br}, 1 \mathrm{H}), 5.45-5.25(\mathrm{~m}, 1 \mathrm{H}), 5.10-4.9(\mathrm{~m}, 1 \mathrm{H}), 4.75-$ $4.55(\mathrm{~m}, 1 \mathrm{H}), 4.0-3.8(\mathrm{~m}, 1 \mathrm{H}), 3.17(\mathrm{~s}, 3 \mathrm{H}), 2.45-2.2(\mathrm{~m}, 1 \mathrm{H}), 2.14-1.95(\mathrm{~m}, 1 \mathrm{H}), 1.86-1.75$ $(\mathrm{m}, 1 \mathrm{H}), 1.49(\mathrm{~s}, 18 \mathrm{H}), 1.47(\mathrm{~s}, 18 \mathrm{H}), 1.2-1.05(\mathrm{~m}, 1 \mathrm{H}), 1.05-0.9(\mathrm{~m}, 1 \mathrm{H}) ; \mathrm{MS}(\mathrm{m} / \mathrm{e})$ (positive-FAB) $678\left(\mathrm{M}^{+}+\mathrm{H}\right)$.

\section{(1'R,2' $S, 4$ 'S,5'S)-4-(2-Bromo-6-methylamino-9H-purin-9-yl)-1-(di-tert-} butoxyphosphoryloxymethyl)bicyclo[3.1.0]-hex-2-yl-phosphoric Acid Di-tert-butyl Ester (45)

To a solution of triphenylphosphine $(15 \mathrm{mg}, 0.057 \mathrm{mmol})$ in anhydrous THF $(0.5 \mathrm{~mL})$ was added DIAD $(12 \mu \mathrm{L}, 0.057 \mathrm{mmol})$ dropwise at $0{ }^{\circ} \mathrm{C}$ under a nitrogen atmosphere, and the mixture was stirred at this temperature for 20 min until the solution turned red. This reaction mixture was added slowly to a cold stirred solution of alcohol $34(9.2 \mathrm{mg}, 0.0174 \mathrm{mmol})$ and $38(13.1 \mathrm{mg}, 0.057 \mathrm{mmol})$ under a nitrogen atmosphere. The reaction mixture was stirred in an ice bath for $30 \mathrm{~min}$ and then allowed to warm to room temperature while stirring continued for $12 \mathrm{~h}$. Solvent was removed by nitrogen purge, and the residue was purified by preparative thin-layer chromatography $\left(\mathrm{MeOH} / \mathrm{CHCl}_{3}=1 / 20\right)$ to produce $45(3.1 \mathrm{mg}, 23 \%)$ as a thick liquid: ${ }^{1} \mathrm{H}$ NMR $\left(\mathrm{CDCl}_{3}\right) \delta 8.05(\mathrm{~s}, 1 \mathrm{H}), 5.92(\mathrm{br}, 1 \mathrm{H}), 5.45-5.25(\mathrm{~m}, 1 \mathrm{H}), 5.15-$ $5.0(\mathrm{~m}, 1 \mathrm{H}), 4.75-4.55(\mathrm{~m}, 1 \mathrm{H}), 3.95-3.80(\mathrm{~m}, 1 \mathrm{H}), 3.18(\mathrm{~s}, 3 \mathrm{H}), 2.4-2.2(\mathrm{~m}, 1 \mathrm{H}), 2.20-2.0$ $(\mathrm{m}, 1 \mathrm{H}), 1.85-1.7(\mathrm{~m}, 1 \mathrm{H}), 1.58(\mathrm{~s}, 18 \mathrm{H}), 1.49(\mathrm{~s}, 18 \mathrm{H}), 1.2-1.05(\mathrm{~m}, 1 \mathrm{H}), 1.05-0.9(\mathrm{~m}$, $1 \mathrm{H}) ; \mathrm{MS}(\mathrm{m} / \mathrm{e})$ (positive-FAB) $738\left(\mathrm{M}^{+}+\mathrm{H}\right)$. 
(1'R,2'S,4'S,5'S)-Phosphoric Acid Di-tert-butyl Ester 1-(Di-tertbutoxyphosphoryloxymethyl)-4-(2-iodo-6-methylaminopurin-9-yl)bicyclo[3.1.0]hex-2-yl Ester (46)

The alcohol 34 (10 mg, $0.0189 \mathrm{mmol})$, triphenylphosphine (20 mg, $0.0756 \mathrm{mmol})$, and 2iodo-6-methylaminopurine 39 (10.4 $\mathrm{mg}, 0.0378 \mathrm{mmol})$ were mixed and dried under high vacuum for $\sim 30 \mathrm{~min}$. The residue was dissolved in anhydrous tetrahydrofuran $(1 \mathrm{~mL})$ and cooled to $0{ }^{\circ} \mathrm{C}$. Diethyl azodicarboxylate (DEAD, $9.9 \mathrm{mg}, 0.0567 \mathrm{mmol}$ ) was added dropwise via syringe to this solution. After the solution was stirred for $2 \mathrm{~h}$ at room temperature (the progress of the reaction was monitored by thin-layer chromatography), tetrahydrofuran was removed in vacuo. The residue was purified by preparative thin-layer chromatography $\left(\mathrm{CHCl}_{3} / \mathrm{MeOH}=20 / 1\right)$ to give the desired 2-iodo bis(di-tert-butyl phosphate) derivative $46(7.1 \mathrm{mg}, 48 \%):{ }^{1} \mathrm{H}$ NMR $\left(\mathrm{CDCl}_{3}\right) \delta 7.98(\mathrm{~s}, 1 \mathrm{H}), 5.85(\mathrm{bs}, 1 \mathrm{H},-$ NH), 5.35 (dd, $1 \mathrm{H}, J=7.7,14.3 \mathrm{~Hz}), 5.07(\mathrm{~d}, 1 \mathrm{H}, J=6.9 \mathrm{~Hz}), 4.66(\mathrm{dd}, 1 \mathrm{H}, J=4.7,11.0$ $\mathrm{Hz}), 3.91(\mathrm{dd}, 1 \mathrm{H}, J=6.6,11.3 \mathrm{~Hz}$ ), 3.17 (bs, 3H), 2.31 (dd, $1 \mathrm{H}, J=8.0,15.4 \mathrm{~Hz}), 2.09$ (dt, $1 \mathrm{H}, J=8.2,14.8 \mathrm{~Hz}), 1.76(\mathrm{dd}, 1 \mathrm{H}, J=4.4,8.5 \mathrm{~Hz}), 1.32(\mathrm{~s}, 18 \mathrm{H}), 1.29(\mathrm{~s}, 9 \mathrm{H}), 1.26(\mathrm{~s}$, 9H), $1.10(\mathrm{dd}, 1 \mathrm{H}, J=4.1,6.0 \mathrm{~Hz}), 0.99(\mathrm{~m}, 1 \mathrm{H})$; MS $(\mathrm{m} / \mathrm{e})\left(\right.$ positive-FAB) $786.3\left(\mathrm{M}^{+}+1\right)$.

\section{2-Amino-6-chloropurin-9-ylmethyl 2,2-Dimethylpropionate (54)}

2-Amino-6-chloropurine 20 (1.00 g, $5.90 \mathrm{mmol})$ was dissolved in DMSO $(5.0 \mathrm{~mL})$ under heating. To this solution were added DMF $(20.0 \mathrm{~mL})$, chloromethyl pivalate $\mathbf{5 3}(1.0 \mathrm{~mL}$, $6.94 \mathrm{mmol})$, and $\mathrm{K}_{2} \mathrm{CO}_{3}(990 \mathrm{mg}, 7.16 \mathrm{mmol})$, and the mixture was stirred at room temperature for 3 days. The reaction mixture was filtered and the filtrate was evaporated. The obtained residue was purified by flash chromatography $(\mathrm{AcOEt} /$ petroleum ether $=2 / 1$ ) and recrystallized from AcOEt/petroleum ether, which furnished 54 (1.33 g, 79\%): ${ }^{1} \mathrm{H}$ NMR $\left(\mathrm{CDCl}_{3}\right) \delta 8.01(\mathrm{~s}, 1 \mathrm{H}), 6.00(\mathrm{~s}, 2 \mathrm{H}), 5.20(\mathrm{bs}, 2 \mathrm{H}), 1.18(\mathrm{~s}, 9 \mathrm{H}) ; \mathrm{MS}(\mathrm{m} / \mathrm{e})$ (positive-FAB) 284, 286 (peak height ratio 3:1) $\left(\mathrm{M}^{+}+1\right)$.

\section{6-Chloro-2-iodopurin-9-ylmethyl 2,2-Dimethylpropionate (55)}

To a solution of 2-amino-6-chloropurin-9-yl-methyl 2,2-dimethylpropionate 54 (704 mg, $2.48 \mathrm{mmol})$ in $\mathrm{MeCN}(2.0 \mathrm{~mL})$ were added diiodomethane $(8.0 \mathrm{~mL})$ and tert-butylnitrite $(0.90 \mathrm{~mL}, 9.99 \mathrm{mmol})$, and oxygen was purged by $\mathrm{N}_{2}$ bubbling. The tube was sealed and the contents stirred at $80{ }^{\circ} \mathrm{C}$ for $2.5 \mathrm{~h}$. The solvent was removed under vacuum and the obtained residue was purified by flash chromatography (AcOEt/petroleum ether $=1 / 2)$, which furnished $55(561 \mathrm{mg}, 57 \%):{ }^{1} \mathrm{H}$ NMR $\left(\mathrm{CDCl}_{3}\right) 8.29(\mathrm{~s}, 1 \mathrm{H}), 6.14(\mathrm{~s}, 2 \mathrm{H}), 1.19(\mathrm{~s}, 9 \mathrm{H}) ; \mathrm{MS}$ $(\mathrm{m} / \mathrm{e})$ (positive-FAB) 395, 397 (peak height ratio 3:1) $\left(\mathrm{M}^{+}+1\right)$.

\section{6-Chloro-2-iodopurine (43)}

To a solution of 6-chloro-2-iodopurin-9-ylmethyl 2,2-dimethylpropionate $\mathbf{5 5}$ (125 mg, 0.317 $\mathrm{mmol})$ in $i-\mathrm{PrOH}(5.0 \mathrm{~mL})$ and $\mathrm{H}_{2} \mathrm{O}(0.500 \mathrm{~mL})$ was added $5 \mathrm{~N}$ aq $\mathrm{NaOH}(0.200 \mathrm{~mL})$ and the mixture stirred at room temperature for 3 days. The solvent was removed under reduced pressure, the residue was poured into saturated aq $\mathrm{NaHCO}_{3}$ and extracted with THF-AcOEt. The organic layer was washed with brine, dried over $\mathrm{Na}_{2} \mathrm{SO}_{4}$, and evaporated. The residue obtained was purified by flash chromatography (AcOEt), which furnished $\mathbf{4 3}$ (42 mg, 48\%): ${ }^{1} \mathrm{H}$ NMR (DMSO) $\delta 8.63(\mathrm{~s}, 1 \mathrm{H})$; MS $(\mathrm{m} / \mathrm{e})$ (positive-FAB) 281, 283 (peak height ratio $3: 1)\left(\mathrm{M}^{+}+1\right)$.

(1'R,2'S,4'S,5'S)-Phosphoric Acid Di-tert-butyl Ester 1-(Di-tertbutoxyphosphoryloxymethyl)-4-(6-chloro-2-iodopurin-9-yl)bicyclo[3.1.0]hex-2-yl Ester (51)

To a solution of triphenylphosphine $(70 \mathrm{mg}, 0.26 \mathrm{mmol})$ in anhydrous THF $(0.50 \mathrm{~mL})$ was added DEAD $(0.035 \mathrm{~mL}, 0.22 \mathrm{mmol})$ dropwise at $-20^{\circ} \mathrm{C}$ with stirring for $1.0 \mathrm{~h}$. Compound $34(18 \mathrm{mg}, 0.035 \mathrm{mmol})$ and 6-chloro-2-iodopurine 43 (65 mg, $0.23 \mathrm{mmol})$ in THF (1.50 
$\mathrm{mL}$ ) were added to the reaction mixture and it stirred at room temperature for 3 days. The solvent was removed under vacuum and the residue obtained was purified by preparative thin-layer chromatography (AcOEt), which furnished $51(15.5 \mathrm{mg}, 57 \%):{ }^{1} \mathrm{H} \mathrm{NMR}\left(\mathrm{CDCl}_{3}\right)$ $\delta 8.44(\mathrm{~s}, 1 \mathrm{H}), 5.34(\mathrm{dd}, 1 \mathrm{H}, J=8.1,15.0 \mathrm{~Hz}), 5.16(\mathrm{~d}, 1 \mathrm{H}, J=6.9 \mathrm{~Hz}), 4.69(\mathrm{dd}, 1 \mathrm{H}, J=$ $5.1,11.4 \mathrm{~Hz}), 3.94(\mathrm{dd}, 1 \mathrm{H}, J=6.6,11.4 \mathrm{~Hz}), 2.40-2.30(\mathrm{~m}, 1 \mathrm{H}), 2.22-2.10(\mathrm{~m}, 1 \mathrm{H}), 1.85-$ $1.80(\mathrm{~m}, 1 \mathrm{H}), 1.50(\mathrm{~s}, 9 \mathrm{H}), 1.49(\mathrm{~s} \times 2,18 \mathrm{H}), 1.48(\mathrm{~s}, 9 \mathrm{H}), 1.18-1.14(\mathrm{~m}, 1 \mathrm{H}), 1.09-1.03(\mathrm{~m}$, $1 \mathrm{H}) ; \mathrm{MS}(\mathrm{m} / \mathrm{e})$ (positive-FAB) 791, 793 (peak height ratio 3:1) $\left(\mathrm{M}^{+}+1\right)$.

\section{(1'R,2'S,4'S,5'S)-Phosphoric Acid Di-tert-butyl Ester 1-(Di-tert- butoxyphosphoryloxymethyl)-4-(2-iodo-6-methylaminopurin-9-yl)bicyclo[3.1.0]hex-2-yl Ester (46)}

To a solution of 6-chloro-2-methylpurin-9-ylmethyl 2,2-dimethylpropionate $\mathbf{5 1}$ (13.0 mg, $0.016 \mathrm{mmol})$ in THF $(0.10 \mathrm{~mL})$ was added $2.0 \mathrm{~N} \mathrm{MeNH}_{2}$ in THF $(1.0 \mathrm{~mL})$ and the mixture stirred for $3 \mathrm{~h}$. The solvent was removed under reduced pressure and the obtained residue was purified by flash chromatography $\left(\mathrm{CHCl}_{3} / \mathrm{MeOH}=5 / 1\right)$, which furnished $46(6.1 \mathrm{mg}$, $47 \%)$.

\section{6-Chloro-2-trimethylstannylpurin-9-ylmethyl 2,2-Dimethylpropionate (56)}

To a solution of 6-chloro-2-iodopurin-9-ylmethyl 2,2-dimethylpropionate $\mathbf{5 5}$ (323 mg, 0.819 $\mathrm{mmol})$ and $\mathrm{PdCl}_{2}\left(\mathrm{PPh}_{3}\right)_{2}(30 \mathrm{mg}, 0.043 \mathrm{mmol})$ in dioxane $(0.75 \mathrm{~mL})$ was added $\mathrm{Me}_{3} \mathrm{SnSnMe}_{3}(820 \mathrm{mg}, 2.50 \mathrm{mmol})$ in dioxane $(2.0 \mathrm{~mL})$ and the mixture stirred at $100{ }^{\circ} \mathrm{C}$ for $5 \mathrm{~h}$. The solvent was removed under vacuum and the residue obtained was purified by flash chromatography (AcOEt/petroleum ether $=1 / 2)$, which furnished $56(310 \mathrm{mg}$, $88 \%):{ }^{1} \mathrm{H} \mathrm{NMR}\left(\mathrm{CDCl}_{3}\right) \delta 8.26(\mathrm{~s}, 1 \mathrm{H}), 6.21(\mathrm{~s}, 2 \mathrm{H}), 1.18(\mathrm{~s}, 9 \mathrm{H}), 0.45(\mathrm{~s}, 9 \mathrm{H}) ; \mathrm{MS}(\mathrm{m} / \mathrm{e})$ (positive-FAB) 431 $\left(\mathrm{M}^{+}+1\right)$.

\section{6-Chloro-2-methylpurin-9-ylmethyl 2,2-Dimethylpropionate (57)}

A mixture of tris(dibenzylideneacetone)dipalladium( $(0)$ chloroform adduct $\left(\mathrm{Pd}_{2}(\mathrm{dba})_{3}, 16\right.$ $\mathrm{mg}, 0.031 \mathrm{mmol})$, tri $o$-tolylphosphine $\left(\mathrm{P}(o-\mathrm{Tol})_{3}, 31 \mathrm{mg}, 0.102 \mathrm{mmol}\right), \mathrm{CuBr}(19 \mathrm{mg}, 0.135$ $\mathrm{mmol})$, and $\mathrm{K}_{2} \mathrm{CO}_{3}(26 \mathrm{mg}, 0.188 \mathrm{mmol})$ in a flask was dried under reduced pressure, and the vacuum was replaced by dry nitrogen. A solution of 6-chloro-2-trimethylstannylpurin-9ylmethyl 2,2-dimethylpropionate 56 (109 $\mathrm{mg}, 0.253 \mathrm{mmol})$ in DMF (2.0 mL) and MeI (0.15 $\mathrm{mL}, 2.41 \mathrm{mmol}$ ) was added, and the mixture was stirred at $60{ }^{\circ} \mathrm{C}$ for $3 \mathrm{~h}$. The resulting reaction mixture was directly pass through a short column $\left(\mathrm{SiO}_{2}, 2.0 \mathrm{~mL}\right.$, eluent $\left.\mathrm{AcOEt}\right)$ and evaporated. The residue obtained was purified by flash chromatography (AcOEt/petroleum ether $=1 / 2)$, which furnished $57(45 \mathrm{mg}, 62 \%):{ }^{1} \mathrm{H} \mathrm{NMR}\left(\mathrm{CDCl}_{3}\right) \delta 8.29(\mathrm{~s}, 1 \mathrm{H}), 6.16(\mathrm{~s}$, $2 \mathrm{H}), 2.83(\mathrm{~s}, 3 \mathrm{H}), 1.18(\mathrm{~s}, 9 \mathrm{H})$; MS ( $\mathrm{m} / \mathrm{e}$ ) (positive-FAB) 283, 285 (peak height ratio 3:1) $\left(\mathrm{M}^{+}+1\right)$.

\section{6-Methylamino-2-methylpurine (40)}

To a solution of 6-chloro-2-methylpurin-9-yl-methyl 2,2-dimethylpropionate 57 (34 mg, $0.120 \mathrm{mmol})$ in THF $(1.0 \mathrm{~mL})$ was added $2.0 \mathrm{~N} \mathrm{MeNH}_{2}$ in THF $(2.0 \mathrm{~mL})$ and the mixture stirred for $22 \mathrm{~h}$. The solvent was removed under reduced pressure and the obtained residue was purified by preparative thin-layer chromatography (first, AcOEt; second, $\mathrm{CHCl}_{3} / \mathrm{MeOH}$ $=5 / 1)$, which also furnished 6-methylamino-2-methylpurine $\mathbf{4 0}(27 \mathrm{mg}, 81 \%)$ and 6methylamino-2-methylpurin-9-ylmethyl 2,2-dimethylpropionate (4 mg, 12\%): ${ }^{1} \mathrm{H} \mathrm{NMR}$ (DMSO) $\delta 7.96(\mathrm{~s}, 1 \mathrm{H}), 7.40(\mathrm{bs}, 1 \mathrm{H}), 2.94(\mathrm{~s}, 3 \mathrm{H}), 2.40(\mathrm{~s}, 3 \mathrm{H})$; MS (m/e) (positive-FAB) $164\left(\mathrm{M}^{+}+1\right)$. 


\section{6-Methylamino-2-methylpurin-9-yl-methyl 2,2-dimethylpropionate}

${ }^{1} \mathrm{H}$ NMR (DMSO) $\delta 8.11(\mathrm{~s}, 1 \mathrm{H}), 7.65$ (bs, 1H), 6.10 (s, 2H), 2.94 (s, 3H), 2.44 (s, 3H), 1.10 $(\mathrm{s}, 9 \mathrm{H}) ; \mathrm{MS}(\mathrm{m} / \mathrm{e})$ (positive-FAB) $278\left(\mathrm{M}^{+}+1\right)$.

(1'R,2'S,4'S,5'S)-Phosphoric Acid Di-tert-butyl Ester 1-(Di-tertbutoxyphosphoryloxymethyl)-4-(2-methyl-6-methylaminopurin-9-yl)bicyclo[3.1.0]hex-2-yl Ester (47)

To a solution of triphenylphosphine $(52 \mathrm{mg}, 0.198 \mathrm{mmol})$ in anhydrous THF $(0.40 \mathrm{~mL})$ was added DEAD $(0.030 \mathrm{~mL}, 0.191 \mathrm{mmol})$ dropwise at $-20{ }^{\circ} \mathrm{C}$ with stirring for $1.0 \mathrm{~h}$. Compound $34(16.0 \mathrm{mg}, 0.030 \mathrm{mmol})$ and 6-methylamino-2-methylpurine $40(27 \mathrm{mg}$, $0.0975 \mathrm{mmol})$ in THF $(1.50 \mathrm{~mL})$ were added to the reaction mixture, which stirred at room temperature for $3 \mathrm{~d}$. The solvent was removed under vacuum and the residue obtained was purified by preparative thin-layer chromatography (AcOEt), which furnished 47 (10.0 mg, 49\%): ${ }^{1} \mathrm{H}$ NMR $\left(\mathrm{CDCl}_{3}\right) \delta 7.99(\mathrm{~s}, 1 \mathrm{H}), 5.62(\mathrm{br}, 1 \mathrm{H}), 5.38(\mathrm{~m}, 1 \mathrm{H}), 5.09(\mathrm{~d}, 1 \mathrm{H}, J=6.9$ $\mathrm{Hz}), 4.65(\mathrm{dd}, 1 \mathrm{H}, J=4.5,11.4 \mathrm{~Hz}), 3.92(\mathrm{dd}, 1 \mathrm{H}, J=6.3,11.4 \mathrm{~Hz}), 3.22(\mathrm{~s}, 3 \mathrm{H}), 2.60(\mathrm{~s}$, $3 \mathrm{H}), 2.40-2.29(\mathrm{~m}, 1 \mathrm{H}), 2.18-2.05(\mathrm{~m}, 1 \mathrm{H}), 1.80(\mathrm{~m}, 1 \mathrm{H}), 1.49(\mathrm{~s}, 18 \mathrm{H}), 1.47(\mathrm{~s}, 9 \mathrm{H}), 1.45$ (s, 9H), 1.13-1.08 (m, 1H), 1.01-0.95 (m, 1H).

(1'R,2'S,4'S,5'S)-Phosphoric Acid Di-tert-butyl Ester 1-(Di-tertbutoxyphosphoryloxymethyl)-4-(2-hexyl-6-methylaminopurin-9-yl)bicyclo[3.1.0]hex-2-yl Ester (48)

2-Hexynyl bis(di-tert-butyl phosphate) derivative $\mathbf{5 0}(13 \mathrm{mg}, 0.0176 \mathrm{mmol})$ was dissolved in methanol $(5 \mathrm{~mL})$, and $5 \% \mathrm{Pd} / \mathrm{C}(150 \mathrm{mg})$ was added. The reaction flask was applied to a vacuum and filled with hydrogen several times. The reaction mixture was stirred for $2 \mathrm{~h}$ at room temperature under a hydrogen balloon. The resulting mixture was filtrated through a pad of Celite and washed with methanol $(5 \mathrm{~mL} \times 3)$. The residue was purified by preparative thin-layer chromatography $\left(\mathrm{CHCl}_{3} / \mathrm{MeOH}=20 / 1\right)$ to give the desired 2-hexanyl bis(di-tertbutyl phosphate) derivative $48(11.5 \mathrm{mg}, 88 \%):{ }^{1} \mathrm{H}$ NMR $\left(\mathrm{CDCl}_{3}\right) \delta 8.02(\mathrm{~s}, 1 \mathrm{H}), 5.62$ (bs, $1 \mathrm{H},-\mathrm{NH}), 5.35(\mathrm{dd}, 1 \mathrm{H}, J=7.7,14.6 \mathrm{~Hz}), 5.12(\mathrm{~d}, 1 \mathrm{H}, J=6.9 \mathrm{~Hz}), 4.64(\mathrm{dd}, 1 \mathrm{H}, J=4.4$, $11.0 \mathrm{~Hz}), 3.90(\mathrm{dd}, 1 \mathrm{H}, J=6.3,11.0 \mathrm{~Hz}), 3.23(\mathrm{~d}, 3 \mathrm{H}, J=4.9 \mathrm{~Hz}), 2.81(\mathrm{dd}, 2 \mathrm{H}, J=7.7,8.0$ $\mathrm{Hz}), 2.34(\mathrm{dd}, 1 \mathrm{H}, J=7.7,15.1 \mathrm{~Hz}), 2.09(\mathrm{dt}, 1 \mathrm{H}, J=8.0,15.7 \mathrm{~Hz}), 1.23-1.88(\mathrm{~m}, 9 \mathrm{H})$, 1.497 (s, 9H), 1.489 (s, 9H), 1.479 (s, 9H), $1.455(\mathrm{~s}, 9 \mathrm{H}), 1.13(\mathrm{dd}, 1 \mathrm{H}, J=4.4,5.8 \mathrm{~Hz}), 0.98$ $(\mathrm{dd}, 1 \mathrm{H}, J=6.3,8.5 \mathrm{~Hz}), 0.89(\mathrm{~m}, 3 \mathrm{H}) ; \mathrm{MS}(\mathrm{m} / \mathrm{e})$ (positive-FAB) $744.5\left(\mathrm{M}^{+}+1\right)$.

(1'R,2'S,4'S,5'S)-Phosphoric Acid Di-tert-butyl Ester 1-(Di-tert-butoxyphosphoryloxymethyl)-4-(2-hex-1-enyl-6-methylaminopurin-9-yl)bicyclo[3.1.0]hex-2-yl Ester (49)

2-Hexenyl bis(di-tert-butyl phosphate) derivative $49(6.1 \mathrm{mg}, 44 \%)$ was prepared by a method similar to that for 46, except 2-hexenyl-6-methylaminopurine $\mathbf{4 1}(10 \mathrm{mg}, 0.0189$ mmol) was used as the starting material: ${ }^{1} \mathrm{H}$ NMR $\left(\mathrm{CDCl}_{3}\right) \delta 8.01(\mathrm{~s}, 1 \mathrm{H}), 7.11(\mathrm{dt}, 1 \mathrm{H}, J=$ 6.9, $15.4 \mathrm{~Hz}), 6.48(\mathrm{dt}, 1 \mathrm{H}, J=1.4,15.6 \mathrm{~Hz}), 5.62(\mathrm{bq}, 1 \mathrm{H},-\mathrm{NH}), 5.38(\mathrm{dd}, 1 \mathrm{H}, J=7.7,14.3$ $\mathrm{Hz}), 5.14(\mathrm{~d}, 1 \mathrm{H}, J=6.9 \mathrm{~Hz}), 4.65(\mathrm{dd}, 1 \mathrm{H}, J=4.7,11.3 \mathrm{~Hz}), 3.91(\mathrm{dd}, 1 \mathrm{H}, J=6.3,11.3$ $\mathrm{Hz}), 3.24(\mathrm{~d}, 3 \mathrm{H}, J=5.0 \mathrm{~Hz}), 2.35(\mathrm{dd}, 1 \mathrm{H}, J=8.5,15.4 \mathrm{~Hz}), 2.29(\mathrm{~m}, 2 \mathrm{H}), 2.11(\mathrm{dt}, 1 \mathrm{H}, J=$ 7.7, $15.4 \mathrm{~Hz}), 1.80$ (dd, $1 \mathrm{H}, J=4.1,8.5 \mathrm{~Hz}), 1.33-1.61(\mathrm{~m}, 4 \mathrm{H}), 1.496(\mathrm{~s}, 9 \mathrm{H}), 1.490$ (s, 9H), 1.482 (s, 9H), 1.446 (s, 9H), $1.13(\mathrm{dd}, 1 \mathrm{H}, J=4.4,5.8 \mathrm{~Hz}), 0.98$ (dd, $1 \mathrm{H}, J=6.3,8.5$ $\mathrm{Hz}), 0.94(\mathrm{~m}, 3 \mathrm{H}) ; \mathrm{MS}(\mathrm{m} / \mathrm{e})$ (positive-FAB) $742.5\left(\mathrm{M}^{+}+1\right)$. 
(1'R,2'S,4'S,5'S)-Phosphoric Acid Di-tert-butyl Ester 1-(Di-tertbutoxyphosphoryloxymethyl)-4-(2-hex-1-ynyl-6-methylaminopurin-9-yl)bicyclo[3.1.0]hex-2yl Ester (50)

2-Hexynyl bis(di-tert-butyl phosphate) derivative $\mathbf{5 0}(20.1 \mathrm{mg}, 72 \%)$ was prepared by a method similar to that for 44, except 2-hexynyl-6-methylaminopurine $\mathbf{4 2}(20 \mathrm{mg}, 0.0378$ mmol) was used as the starting material: ${ }^{1} \mathrm{H}$ NMR $\left(\mathrm{CDCl}_{3}\right) \delta 8.14(\mathrm{~s}, 1 \mathrm{H}), 5.77(\mathrm{bs}, 1 \mathrm{H})$, $5.33(\mathrm{dd}, 1 \mathrm{H}, J=8.2,14.8 \mathrm{~Hz}), 5.21(\mathrm{~d}, 1 \mathrm{H}, J=6.9 \mathrm{~Hz}), 4.67(\mathrm{dd}, 1 \mathrm{H}, J=4.4,11.3 \mathrm{~Hz})$, $3.83(\mathrm{dd}, 1 \mathrm{H}, J=6.6,11.3 \mathrm{~Hz}), 3.25(\mathrm{bs}, 3 \mathrm{H}), 2.46(\mathrm{t}, 2 \mathrm{H}, J=7.1 \mathrm{~Hz}), 2.29(\mathrm{dd}, 1 \mathrm{H}, J=8.0$, $15.4 \mathrm{~Hz}), 2.08(\mathrm{~m}, 1 \mathrm{H}), 1.60-1.82(\mathrm{~m}, 5 \mathrm{H}), 1.499(\mathrm{~s}, 9 \mathrm{H}), 1.488(\mathrm{~s}, 9 \mathrm{H}), 1.472(\mathrm{~s}, 9 \mathrm{H}), 1.462$ $(\mathrm{s}, 9 \mathrm{H}), 1.12(\mathrm{dd}, 1 \mathrm{H}, J=4.4,5.8 \mathrm{~Hz}), 0.9(\mathrm{~m}, 1 \mathrm{H}), 0.94(\mathrm{t}, 3 \mathrm{H}, J=7.1 \mathrm{~Hz}) ; \mathrm{MS}(\mathrm{m} / \mathrm{e})$ (positive-FAB) $740.5\left(\mathrm{M}^{+}+1\right)$.

(1'R,2'S,4'S,5'S)-Phosphoric Acid Di-tert-butyl Ester 1-(Di-tert-butoxyphosphoryloxymethyl)-4-(6-chloro-2-trimethylstannylpurin-9-yl)bicyclo[3.1.0]hex-2-yl Ester (52)

To a solution of $51(2.7 \mathrm{mg}, 0.0034 \mathrm{mmol})$ and $\mathrm{PdCl}_{2}-\left(\mathrm{PPh}_{3}\right)_{2}(3.5 \mathrm{mg}, 0.0050 \mathrm{mmol})$ in dioxane $(0.30 \mathrm{~mL})$ was added $\mathrm{Me}_{3} \mathrm{SnSnMe}_{3}(20 \mathrm{mg}, 0.061 \mathrm{mmol})$ and the mixture stirred at $60{ }^{\circ} \mathrm{C}$ for $3.5 \mathrm{~h}$. The solvent was removed under vacuum and the residue obtained was purified by preparative TLC (AcOEt), which furnished $\mathbf{5 2}(0.7 \mathrm{mg}, 25 \%):{ }^{1} \mathrm{H} \mathrm{NMR}\left(\mathrm{CDCl}_{3}\right)$ $\delta 8.42(\mathrm{~s}, 1 \mathrm{H}), 5.40-5.20(\mathrm{~m}, 2 \mathrm{H}), 4.65(\mathrm{~m}, 1 \mathrm{H}), 3.90(\mathrm{~m}, 1 \mathrm{H}), 2.40-2.25(\mathrm{~m}, 1 \mathrm{H}), 2.25-$ $2.10(\mathrm{~m}, 1 \mathrm{H}), 1.90-1.80(\mathrm{~m}, 1 \mathrm{H}), 1.50(\mathrm{~s}, 9 \mathrm{H}), 1.48(\mathrm{~s}, 18 \mathrm{H}), 1.44(\mathrm{~s}, 9 \mathrm{H}), 1.25-1.20(\mathrm{~m}$, $1 \mathrm{H}), 1.05-1.00(\mathrm{~m}, 1 \mathrm{H}), 0.43(\mathrm{~s}, 9 \mathrm{H})$; MS $(\mathrm{m} / \mathrm{e})$ (positive-FAB) $827\left(\mathrm{M}^{+}+1\right), 849\left(\mathrm{M}^{+}+\mathrm{Na}\right)$.

\section{Small-Scale Conversion of Compound 52 into Compound 12}

A $20 \mu \mathrm{L}(0.35 \mu \mathrm{mol})$ portion of an iodine solution $\left(4.5 \mathrm{mg}\right.$ of $\mathrm{I}_{2}$ in $1.00 \mathrm{~mL}$ of AcOEt $)$ was added to a solution of $\mathbf{5 2}(0.15 \mathrm{mg}, 0.18 \mu \mathrm{mol})$ in AcOEt $(0.100 \mathrm{~mL})$ and the mixture stirred at room temperature for $10 \mathrm{~min}$. Then $0.01 \mathrm{~mL}$ of $5 \%$ aqueous $\mathrm{NaHSO}_{3}$ was added to stop the reaction, and the solvent was removed under vacuum. The residue (crude 29) was dissolved in $5 \% \mathrm{TFA} / \mathrm{CH}_{2} \mathrm{Cl}_{2}(0.50 \mathrm{~mL})$ and stirred for $3 \mathrm{~h}$ at $25^{\circ} \mathrm{C}$. The solvent was removed under reduced pressure, and the residue was quenched by addition of $5.0 \mathrm{~mL}$ of triethylammonium bicarbonate buffer $(1.0 \mathrm{M})$. The mixture was subsequently frozen and lyophilized. The residue (crude 29) was dissolved in $40 \% \mathrm{MeNH}_{2}$ in water $(0.50 \mathrm{~mL})$ and stirred for $3 \mathrm{~h}$ at room temperature. The solvent was removed under reduced pressure. The residue (crude 12) was purified by HPLC (system A or system B).

\section{Enzymatic Synthesis of 5}

ATP ( $20 \mathrm{nmol}, 2 \mu \mathrm{L}$ of a $10-\mathrm{mM}$ solution in water) and polynucleotide kinase (Sigma, 10 IU) were added to $20 \mu \mathrm{L}$ of a buffer consisting of $50 \mathrm{mM}$ Tris $\mathrm{HCl}, 10 \mathrm{mM} \mathrm{MgCl}_{2}, 5 \mathrm{mM}$ dithiothreitol, $0.1 \mathrm{mM}$ spermidine, and $0.1 \mathrm{mM}$ EDTA. The nucleotide substrate $\mathbf{5 8}^{41}(1 \mu \mathrm{L}$ of a 10 - $\mathrm{mM}$ solution in water) was then added, and the mixture was mixed with vortexing and incubated at $37^{\circ} \mathrm{C}$ for the time indicated ( $18 \mathrm{~h}$ incubation was found to be optimal). Aliquots $(10 \mu \mathrm{L})$ were injected for HPLC analysis. A C18 Zorbax column (Agilent) was used, with the flow rate $1 \mathrm{~mL} / \mathrm{min}$ and the mobile phase consisting of a gradient of acetonitrile/0.1 M triethylammonium acetate (aq) of 10/90 to 15/85 in $10 \mathrm{~min}$, then to $30 / 70$ in $10 \mathrm{~min}$. The product of the enzymatic transformation (5) was detected in $\sim 40 \%$ yield, as judged with HPLC. The retention time of the product was $6.2 \mathrm{~min}$, compared with the starting material, which had a retention time of $8.1 \mathrm{~min}$. These three individual peaks were collected and lyophilized. Mass spectrometry (FAB) confirmed the identity of the starting material $(\mathrm{m} / z 387, \mathrm{M}-1)$ and product $5(\mathrm{~m} / z 468, \mathrm{M}-1)$. The side product at retention time 11.6 min displayed an $\mathrm{m} / z$ of 310 , consistent with the corresponding nucleoside $(\mathrm{M}+$ 1). An unidentified impurity present in the starting material was also detected at $7.7 \mathrm{~min}$. 
Compound $\mathbf{5 8}$ was found to be chemically stable. The HPLC profile of a solution in $\mathrm{H}_{2} \mathrm{O}$ / acetonitrile/buffer was unchanged following $60 \mathrm{~h}$ incubation at $37^{\circ} \mathrm{C}$. However, when enzyme was added in the absence of ATP, $\sim 20 \%$ of the compound was dephosphorylated during an incubation of $17 \mathrm{~h}$ to the nucleoside 59 (HPLC retention time $=11.6 \mathrm{~min}$ ). Under the same incubation conditions in the presence of the enzyme, $\mathbf{5}$ was stable.

\section{Pharmacological Analyses}

The affinities of 2-substituted $(N)$-methanocarbo bisphosphate analogues for the human $\mathrm{P}_{2} \mathrm{Y}_{1}$ receptor were directly determined by using $\left[{ }^{3} \mathrm{H}\right] 5$ in a radioligand binding assay, as we recently described in detail. ${ }^{31}$ Briefly, the human $\mathrm{P}_{2} \mathrm{Y}_{1}$ receptor was expressed to high levels in Sf9 insect cells with a recombinant baculovirus. Membranes prepared from these cells were incubated for $30 \mathrm{~min}$ at $4{ }^{\circ} \mathrm{C}$ in the presence of $\sim 20 \mathrm{nM}\left[{ }^{3} \mathrm{H}\right] 5$ and a wide range of concentrations of the newly synthesized analogues. Binding reactions were terminated by the addition of ice-cold tris-(hydroxymethyl)aminomethane (Tris) wash buffer (10 mM Tris, $\mathrm{pH} 7.5$, and $145 \mathrm{mM} \mathrm{NaCl}$ ) to the samples followed by rapid filtration over GF/A glass-fiber filters. Each filter was washed with an additional $4 \mathrm{~mL}$ of wash buffer, and radioactivity retained by the filters was quantified by liquid scintillation spectrometry. All assays were carried out in triplicate, and competition curves for all molecules were generated in three separate experiments. $\mathrm{IC}_{50}$ values were determined from each competition curve, and a $K_{\mathrm{i}}$ value was calculated for each analogue according to the relationship $K_{\mathrm{i}}=\mathrm{IC}_{50} / 1+\left[\left[{ }^{3} \mathrm{H}\right] 5\right] /$ $K_{\mathrm{d}}$ of $\left[{ }^{3} \mathrm{H}\right] \mathbf{5}$, where the $K_{\mathrm{d}}$ of $\left[{ }^{3} \mathrm{H}\right] \mathbf{5}$ determined in separate experiments was $8 \mathrm{nM}$.

P2Y receptor-promoted stimulation of inositol phosphate formation was measured at human $\mathrm{P}_{2} \mathrm{Y}_{1}$ receptors stably expressed in $1321 \mathrm{~N} 1$ human astrocytoma cells as previously described. ${ }^{19,42,43}$ The $K_{0.5}$ values were averaged from three to eight independently determined concentration-effect curves for each compound. Briefly, cells plated in 24-well dishes were labeled in inositol-free medium (DMEM; Gibco, Gaithersburg, MD) containing $1.0 \mu \mathrm{Ci}$ of $2-\left[{ }^{3} \mathrm{H}\right]$ myo-inositol $(20 \mathrm{Ci} / \mathrm{mmol}$; American Radiolabeled Chemicals, Inc., St. Louis, MO) for $18-24 \mathrm{~h}$ in a humidified atmosphere of $95 \%$ air $/ 5 \% \mathrm{CO}_{2}$ at $37{ }^{\circ} \mathrm{C}$. Phospholipase $\mathrm{C}$ activity was measured the following day by quantitating $\left[{ }^{3} \mathrm{H}\right]$ inositol phosphate accumulation after a $10-\mathrm{min}$ incubation at $37^{\circ} \mathrm{C}$ in the presence of $10 \mathrm{mM} \mathrm{LiCl}$. Total $\left[{ }^{3} \mathrm{H}\right]$ inositol phosphates were quantified by anion-exchange chromatography as previously described. ${ }^{42,43}$

\section{Data Analysis}

$\mathrm{IC}_{50}$ values obtained in radioligand binding assays and in assays of inhibition of 2MeSADPstimulated inositol phosphate accumulation were calculated by a four-parameter logistic equation and the GraphPad software package (GraphPad, San Diego, CA). All concentration-effect curves were repeated in at least three separate experiments, carried out in duplicate or triplicate with different membrane preparations or different $1321 \mathrm{~N} 1$ cell cultures.

\section{Results \\ Chemical Synthesis}

We prepared methanocarbocyclic analogues of various bisphosphate derivatives (Table 1) in which fused cyclopropane and cyclopentane rings were fixed the pseudoribose moiety in a rigid $(N)$-envelope conformation. Synthetic intermediates included $O$-benzyl-protected phosphoesters, carbocyclic derivatives, adenine derivatives, and $O$-tert-butyl-protected phosphoesters (Schemes 1-5). The nucleotide analogues 7-18 were prepared in the ammonium salt form according to the methods shown in Schemes 1 and 4 and tested biologically as antagonists at the $\mathrm{P}_{2} \mathrm{Y}_{1}$ receptor (Table 1). Identity was confirmed by NMR 
$\left({ }^{1} \mathrm{H}\right.$ and $\left.{ }^{31} \mathrm{P}\right)$ and high-resolution mass spectrometry (HRMS), and purity was demonstrated with high-performance liquid chromatography (HPLC) in two different solvent systems.

To construct the pseudoribose ring leading to the $2^{\prime}$-deoxy- $(N)$-methanocarba- $2^{\prime}$ deoxyadenosine precursors, a bicyclo[3.1.0]hexane intermediate 19 was prepared by the new, optimized approach of Yoshimura et al., ${ }^{32}$ which used simple starting materials and enzymatic transformations. Scheme 1 illustrates the usual synthetic route to the bisphosphate derivatives, in which the phosphorylation was carried out on the preformed nucleoside precursor. To prepare that nucleoside, a commercially available 2-substituted adenine intermediate, 6-chloro-2-aminopurine 20, was condensed with the protected bicyclohexane derivative 19 via a Mitsunobu reaction to give 21, which was then deprotected to give diol 22. The $3^{\prime}$ - and $5^{\prime}$-hydroxyl groups then were phosphorylated by the phosphoramidite method $^{33}$ using dibenzyl diisopropyl phosphoramidite $\mathbf{2 3}$ to give the benzyl-protected derivative 24. The 2-amino group of $\mathbf{2 4}$ was replaced with an iodo, methylthio, or methylseleno group (protected intermediates 25-27) with the use of a neutral purinyl radical, which was generated transiently from the thermal homolysis of the 2-diazonium intermediate. This was accomplished by using the approach introduced by Nair and Fasbender ${ }^{34}$ for the preparation of 2-methylthio and other 2-derivatives of adenosine. Selenium was selected for inclusion because of its similarity to sulfur and because of its known use in X-ray crystallography of proteins, when incorporated into ligands as a heavy atom. ${ }^{35}$ To introduce an amino or methylamino group at the 6-position, it was necessary to substitute 6-Cl with the corresponding amine, which could be accomplished either before (to give 13) or following (to give $\mathbf{7 , 8 , 1 2}$, or $\mathbf{1 4}$ ) deprotection of the phosphate groups. First we synthesized the $N^{6}$-methyl-2-methylthio derivative 13, following the procedure in Scheme 1. However, we were unable to apply this route for the corresponding $N^{6}$-amino derivative 8 because treatment of $\mathbf{2 6}$ with ammonia to replace the 6-chloro group caused side reactions. Therefore, we carried out an ammonia replacement reaction following deprotection of the benzyl groups to obtain the $N^{6}$-amino derivative 8 . We used similar procedures of phosphoester deprotection followed by replacement of the 6-chloro group for the preparation of the 2-methylseleno derivative $\mathbf{1 4}$.

As an alternate synthetic route to the bisphosphate derivatives, phosphate groups were introduced into a versatile phosporylated bicyclo[3.1.0] hexane precursor 34, protected with tert-butyl ester groups, prior to the Mitsunobu coupling (Scheme 2).

We first attempted to synthesize 2-fluoro $\mathbf{1 0}$ and 2-bromo $\mathbf{1 1}$ derivatives by the approach shown in Scheme 1, which used the phosphoramidite route to phosphorylate the corresponding nucleoside diol derivative. ${ }^{18}$ However, only traces of the products were obtained due to side reactions, which seemed to result from the high nucleophilicity of the 6amino group. Thus, an alternate route was needed. For substitution of the 2-position of the purine ring with bromo or fluoro, the corresponding adenine precursors $\mathbf{3 7}$ and $\mathbf{3 8}$ were prepared (Scheme 3 ). We used $\mathbf{2 0}$, a commercially available material, to prepare the dihaloadenines $\mathbf{3 5}$ and $\mathbf{3 6}$ by a method from the literature. ${ }^{36}$ Subsequent methylamination of the 6-position gave $\mathbf{3 7}$ and $\mathbf{3 8}$, which were coupled with the methanocarba moiety $\mathbf{3 4}$ by a Mitsunobu reaction. 2-Iodo- $N^{6}$-methyladenine 39 was prepared with the method of Nair and Fasbender. ${ }^{34}$ The two 2-alkene/alkyne-substitituted adenines $\mathbf{4 1}$ and $\mathbf{4 2}$ were prepared as previously reported. ${ }^{37}$ These 2-haloadenine derivatives and several 2-C-substituted analogues were incorporated into the nucleoside structure as shown in Scheme 4, via the protected bicyclo[3.1.0]-hexane precursor 34. Following the Mitsunobu reaction, the hexynyl intermediate $\mathbf{5 0}$ was reduced to the corresponding alkane to give 48. Deprotection of the tert-butyl groups was carried out with TFA to give the bisphosphate derivatives 10-12 and 15-18. 
The preparation of additional 2-substituted adenine intermediates, including 6-chloro-2iodopurine $\mathbf{4 3}$ used in Scheme 4, required a separate synthetic strategy (Scheme 5). The adenine precursor $\mathbf{2 0}$ dissolved in polar organic solvents, e.g. pyridine or DMSO, only to a limited extent, which made the selection of transformation conditions difficult. To proceed further, we applied a protecting group at the $\mathrm{N}-9$ position, expecting an improvement in solubility. The pivaloyloxymethyl group was chosen as the protecting group, and $\mathbf{5 4}$ was prepared with the method of Rasmussen and Leonard. ${ }^{41}$ Compound $\mathbf{5 4}$ dissolved well in the usual organic solvents, allowing the 2-iodination of $\mathbf{5 4}$ to be performed by the method of Nair and Fasbender. ${ }^{34}$

With the success of $\left[{ }^{3} \mathrm{H}\right] \mathbf{5}$ as a selective radioligand for $\mathrm{P} 2 \mathrm{Y}_{1}$ receptor characterization, ${ }^{31}$ we sought to design new antagonists in this series as high-affinity receptor probes. As a route to a novel iodinated analogue that could be potentially radiolabeled, we explored the substitution of the iodo group of $\mathbf{1 2}$ (Scheme 4) and its adenine precursors (Scheme 5) with trimethyltin. ${ }^{38,39}$ This provides a means of rapidly obtaining the iodinated ligand $\mathbf{1 2}$. Similar methodology based on trialkyl tin precursors has been used to prepare radioiodinated ligands for SPECT (single photon emission computed tomography). ${ }^{39,40}$ The 2-iodo product $\mathbf{5 5}$ was converted to the 2-trimethylstannyl derivative $\mathbf{5 6}$ by the method of Baranowska-Kortylewicz et al. ${ }^{42}$ Compound $\mathbf{5 6}$ was a useful intermediate because it could serve as a suitable substrate for Stille coupling; thus, we decided to prepare the 2-methyl derivative. Compound $\mathbf{5 6}$ reacted with methyl iodide under the conditions of Suzuki et al. ${ }^{43}$ The product $\mathbf{5 7}$ was treated with methylamine to make $\mathbf{4 0}$, which was coupled with the methanocarba moiety by a Mitsunobu reaction. Deprotection was carried out with TFA to give the bisphosphate derivative $\mathbf{1 5}$.

As an alternate route to introduce iodine in the antagonist 12, we also attempted stannylation of $\mathbf{4 6}$ with the method of Baranowska-Kortylewicz et al., to be followed by reiodination. ${ }^{42}$ However, we obtained only the 2-H derivative, which formed upon replacement of the trimethylstannyl group by hydrogen, which was readily available from an acidic proton such as the 6-NH(Me). As an alternative (Scheme 4), we tried stannylation using a 6-chloro derivative 51. This intermediate was synthesized from $\mathbf{4 3}$, which was obtained by hydrolysis of $\mathbf{5 5}$, and was coupled with the methanocarba moiety by a Mitsunobu reaction. Intermediate $\mathbf{5 1}$ was successfully stannylated with the method of Baranowska-Kortylewicz et al. ${ }^{42}$ The trimethyl stannyl derivative $\mathbf{5 2}$ reacted with iodine (which could be generated rapidly from iodide) and re-formed 51. By mass spectral analysis of the iodination reaction at various time points (1-40 $\mathrm{min}$ ), an optimal reaction time was determined to be $10 \mathrm{~min}$. Deprotection of $\mathbf{5 1}$ on a small scale with TFA was accomplished to give the bisphosphate derivative 29, which was then converted to the antagonist 12 (Scheme 1).

We have explored a synthetic methodology that would allow a phosphate group to be incorporated in a potent $\mathrm{P} 2 \mathrm{Y}_{1}$ receptor antagonist in the final synthetic step. Although chemical phosphorylation methods were used until now to prepare $\mathrm{P}_{2} \mathrm{Y}_{1}$ receptor antagonists in this series, we devised an enzymatic method for the phosphorylation at the $5^{\prime}$ position, leading to compound 5. This method (Scheme 6) is based on phosphorylation with polynucleotide kinase (EC 2.7.1.78). ${ }^{44}$ The $3^{\prime}$-monophosphorylated intermediate $\mathbf{5 8}^{45}$ was treated with the enzyme and ATP as the phosphate source. Following incubation for $60 \mathrm{~min}$, the product 5 was detected in $\sim 40 \%$ yield, as judged by using HPLC. The intermediate $\mathbf{5 8}$ was found to be chemically stable under the incubation conditions. A side reaction, removal of the $3^{\prime}$-phosphate group of $\mathbf{5 8}$ to yield the nucleoside analogue $\mathbf{5 9}$, occurred to a significant degree only in the absence of ATP. 


\section{Pharmacological Activity}

We recently developed $\left[{ }^{3} \mathrm{H}\right] \mathbf{5}$ as a high-affinity and selective radioligand for quantification of the $\mathrm{P}_{2} \mathrm{Y}_{1}$ receptor. ${ }^{31}$ Therefore, the human $\mathrm{P}_{2} \mathrm{Y}_{1}$ receptor can be expressed from a baculovirus to high levels in Sf9 insect cells, and membranes prepared from these cells can be labeled specifically with $\left[{ }^{3} \mathrm{H}\right] \mathbf{5}$ to directly assess the affinity of newly synthesized molecules at the $\mathrm{P}_{2} \mathrm{Y}_{1}$ receptor. Therefore, human $\mathrm{P}_{2} \mathrm{Y}_{1}$ receptor-expressing membranes were incubated with $10 \mathrm{nM}\left[{ }^{3} \mathrm{H}\right] \mathbf{5}$ and a wide range of concentrations of 2-substituted (N)methanocarba bisphosphate analogues. As illustrated in Figure 1, all of the bisphosphate derivatives tested interacted with the $\mathrm{P}_{2} \mathrm{Y}_{1}$ receptor, as shown by their capacity to inhibit $\left[{ }^{3} \mathrm{H}\right] 5$ binding, and this inhibition occurred with kinetics consistent with interaction by the law of mass action kinetics at a single site. $\mathrm{IC}_{50}$ values were determined (Table 1) from each competition curve, and a $K_{\mathrm{i}}$ value was calculated for each analogue according to the relationship $K_{\mathrm{i}}=\mathrm{IC}_{50} / 1+\left[\left[{ }^{3} \mathrm{H}\right] \mathbf{5}\right] / K_{\mathrm{d}}$ of $\left[{ }^{3} \mathrm{H}\right] \mathbf{5}$.

We also tested the functional activities of $(N)$-methanocarba bisphosphate analogues as agonists and antagonists at the human $\mathrm{P}_{2} \mathrm{Y}_{1}$ receptor stably expressed in $1321 \mathrm{~N} 1$ human astrocytoma cells (Table 1). Agonist activity was tested by measuring the capacity of molecules to increase inositol phosphate accumulation by activating the phospholipase Ccoupled $\mathrm{P}_{2} \mathrm{Y}_{1}$ receptor, and antagonist activity at the $\mathrm{P}_{2} \mathrm{Y}_{1}$ receptor was assessed by measuring the capacity of these molecules to inhibit 2-methylthio-adenosine $5^{\prime}$-diphosphate (2Me-SADP)-stimulated accumulation of inositol phosphates.

None of these 2-substituted molecules exhibited agonist activity in the $1321 \mathrm{~N} 1$ cell-test system, but all displayed a capacity to inhibit 2MeSADP-stimulated inositol phosphate accumulation, with an $\mathrm{IC}_{50}$ value consistent with their $K_{\mathrm{i}}$ values determined in binding experiments. Within the series of 2-halo analogues, the most potent antagonist in both functional and binding models was a $(N)$-methanocarba-2-iodo analogue 12, and all other 2halo derivatives were clearly less potent. This derivative displayed a $K_{\mathrm{i}}$ value in competition for binding of $\left[{ }^{3} \mathrm{H}\right] \mathbf{5}$ at the $\mathrm{hP} 2 \mathrm{Y}_{1}$ receptor of $0.79 \mathrm{nM}$. The $N^{6}$-methyl derivative 12 was 16 fold more potent in binding than the corresponding 6-amino analogue 7 . The corresponding $N^{6}$-methyl 2-bromo and 2-chloro derivatives $\mathbf{1 1}$ and $\mathbf{5}$ exhibited similar $K_{\mathrm{i}}$ values and affinities that were 5-10-fold less than that for 12, and the fluoro derivative $\mathbf{1 0}$ exhibited a much lower affinity (Figure 1$)$. The $(N)$-methanocarba-2-methylthio-, 2-methylseleno, 2hexyl, 2-(1-hexenyl), and 2-(1-hexynyl) analogues exhibited lower affinities than did most of the 2-halo derivatives, with $K_{\mathrm{i}}$ values in the micromolar range observed for these compounds at $\mathrm{P} 2 \mathrm{Y}_{1}$ receptors. No significant difference was observed between the alkene and alkyne derivatives $\mathbf{1 7}$ and $\mathbf{1 8}$, whereas the corresponding alkane 16 exhibited a 4-5fold-lower affinity, with a $K_{\mathrm{i}}$ value in binding calculated to be $80 \mathrm{nM}$. However, the 2methyl derivative $\mathbf{1 5}$ was nearly as potent as the corresponding 2-chloro analogue $\mathbf{5}$.

Schild analysis of antagonism by $\mathbf{1 2}$ of inositol phosphate accumulation in 1321N1 human astrocytoma cells stably expressing the human $\mathrm{P}_{2} \mathrm{Y}_{1}$ receptor, stimulated by 2-MeS-ADP, was carried out (Figure 2). A $K_{\mathrm{B}}$ value of $1.74 \mathrm{nM}$ was determined, in close agreement with binding data for this compound.

A correlation of binding affinities (expressed as $K_{\mathrm{i}}$ values) and functional antagonistic potencies (expressed as $\mathrm{IC}_{50}$ values) at the human $\mathrm{P}_{2} \mathrm{Y}_{1}$ receptor was examined for nine compounds (Figure 3). The degree of correlation was high, with an $r^{2}$ value of 0.98 . Thus, as we showed recently in radioligand binding assays with $\left[{ }^{3} \mathrm{H}\right] \mathbf{5}$ and previously studied bisphosphate analogues,${ }^{31}$ the radioligand binding assay is a readily applicable predictor of the functional effects of the $\mathrm{P}_{2} \mathrm{Y}_{1}$ receptor antagonists. 


\section{Discussion}

In previous studies, ${ }^{18,20}$ we concluded that substitution of the ribose moiety with the $(N)$ methanocarba ring system provides an enhancement of affinity at the $\mathrm{P}_{2} \mathrm{Y}_{1}$ receptor. We strengthened this conclusion in the present study. For example, the compounds homologous to $\mathbf{8 , 1 2}$, and $\mathbf{1 3}$ were reported in the ribose series, ${ }^{17}$ and the $\mathrm{IC}_{50}$ values in the same phospholipase $\mathrm{C}$ assay in turkey erythrocytes expressing an endogenous $\mathrm{P}_{2} \mathrm{Y}_{1}$ receptor were 1890,891 , and $362 \mu \mathrm{M}$, respectively. This is to be compared to the values for $\mathbf{8 , 1 2}$, and $\mathbf{1 3}$ of 367, 8.4, and $221 \mathrm{nM}$, respectively. Thus, the enhancement achieved upon conformationally constraining the ribose-like ring in the preferred $(N)$-conformation was present in all three cases. However, the degree of enhancement ranged from slight, in the case of the $N^{6}$-methyl-2-methylthio analogue 13, to dramatic, i.e., 106-fold, in the case of the $N^{6}$-methyl-2-iodo analogue $\mathbf{1 2}$.

In the present study, we focused on optimization of the 2-position substitution. Halo substitution demonstrated a potency order of $\mathrm{I}>\mathrm{Br}, \mathrm{Cl}>\mathrm{F}$, which did not correspond to the relative effects of these substitutions in the ribose series. ${ }^{17}$ The 2-alkylthio substitution, which was found to greatly enhance potency in the agonist series, i.e., $5^{\prime}$-mono-, di-, and triphosphates, ${ }^{21-23}$ did not enhance antagonist potency in the present series. This observation is similar to previous findings with other nucleotide antagonists of the $\mathrm{P}_{2} \mathrm{Y}_{1}$ receptor. ${ }^{17}$ In contrast with C-substitution at the 2-position of adenine reported previously ${ }^{24}$ (i.e., 2-methyl in the ribose series), we did not find an enhancement of affinity in the alkene and alkyne analogues synthesized here.

The methods explored in this study for incorporation of iodo and phosphate groups from simple chemical precursors might be suitable for the preparation of radioligands (containing ${ }^{125} \mathrm{I},{ }^{33} \mathrm{P}$, etc.) of high affinity for the $\mathrm{P}_{2} \mathrm{Y}_{1}$ receptor.

In conclusion, we have enhanced the potency of ring-constrained $\mathrm{P}_{2} \mathrm{Y}_{1}$ receptor antagonists by 2-position substitution. The structure-activity relationship (SAR) patterns were not entirely in parallel to the SAR observed in the ribose series. Thus, subtle differences in the mode of receptor binding probably occur between ribose-containing and $(N)$-methanocarba nucleotides. A key finding in this study is that compound $\mathbf{1 2}$ is the most potent antagonist selective for the $\mathrm{P}_{2} \mathrm{Y}_{1}$ receptor yet reported. These findings promise to be useful in defining the microscopic determinants of the binding sites on these receptors and in designing novel pharmacological probes, including radioligands, and/or therapeutic agents.

\section{Acknowledgments}

This work was supported by USPHS grants GM38213 and HL54889 (to T.K.H.). M.O. is on sabbatical from Toray Industries (Kamakura, Japan) and thanks them for financial support. Mass spectral measurements were carried out by Victor Livengood and NMR by Wesley White (NIDDK). We thank Ariel Gross (NIDDK) for proofreading the manuscript.

\section{References}

1. von Kügelgen I, Wetter A. Molecular pharmacology of P2Yreceptors. Naunyn Schmiedebergs Arch. Pharmacol. 2000; 362:310-323. [PubMed: 11111826]

2. Khakh BS, Burnstock G, Kennedy C, King BF, North RA, Seguela P, Voigt M, Humphrey PP. International union of pharmacology. XXIV. Current status of the nomenclature and properties of P2X receptors and their subunits. Pharmacol. Rev. 2001; 53:107-118. [PubMed: 11171941]

3. Hollopeter G, Jantzen HM, Vincent D, Li G, England L, Ramakrishnan V, Yang RB, Nurden P, Nurden A, Julius D, Conley PB. Identification of the platelet ADP receptor targeted by antithrombotic drugs. Nature. 2001; 409:202-207. [PubMed: 11196645] 
4. Communi D, Suarez Gonzalez N, Detheux M, Brézillon S, Lannoy V, Parmentier M, Boeynaems JM. Identification of a novel human ADP receptor coupled to Gi. J. Biol. Chem. 2001; 276:4147941485. [PubMed: 11546776]

5. Abbracchio MP, Boeynaems JM, Barnard EA, Boyer JL, Kennedy C, Miras-Portugal MT, King BF, Gachet C, Jacobson KA, Weisman GA, Burnstock G. The UDP-glucose receptor renamed the P2Y 14 receptor. Trends Pharmacol. Sci. 2003; 24:52-55. [PubMed: 12559763]

6. Chambers JK, Macdonald LE, Sarau HM, Ames RS, Freeman K, Foley JJ, Zhu Y, McLaughlin MM, Murdock P, McMillan L, Trill J, Swift A, Aiyar N, Taylor P, Vawter L, Naheed S, Szekeres P, Hervieu G, Scott C, Watson JM, Murphy AJ, Duzic E, Klein C, Bergsma DJ, Wilson S, Livi GP. A G protein-coupled receptor for UDP-glucose. J. Biol. Chem. 2000; 275:10767-10771. [PubMed: 10753868]

7. Mohanty JG, Raible DG, McDermott LJ, Pelleg A, Schulman ES. Effects of purine and pyrimidine nucleotides on intracellular $\mathrm{Ca}^{2+}$ in human eosinophils: Activation of purinergic P2Y receptors. J. Allergy Clin. Immunol. 2001; 107:849-855. [PubMed: 11344352]

8. Janssens R, Communi D, Pirotton S, Samson M, Parmentier M, Boeynaems JM. Cloning and tissue distribution of the human $\mathrm{P}_{2} \mathrm{Y}_{1}$ receptor. Biochem. Biophys. Res. Commun. 1996; 221:588-593. [PubMed: 8630005]

9. Webb TE, Simon J, Krishek BJ, Bateson AN, Smart TG, King BF, Burnstock G, Barnard EA. Cloning and functional expression of a brain G-protein-coupled ATP receptor. FEBS Lett. 1993; 324:219-225. [PubMed: 8508924]

10. Moore D, Chambers J, Waldvogel H, Faull R, Emson PJ. Regional and cellular distribution of the $\mathrm{P}_{2} \mathrm{Y}_{1}$ purinergic receptor in the human brain: Striking neuronal localisation. Comput. Neurol. 2000; 421:374-384.

11. Franke H, Krugel U, Schmidt R, Grosche J, Reichenbach A, Illes P. P2 receptor-types involved in astrogliosis in vivo. Br. J. Pharmacol. 2001; 134:1180-1189. [PubMed: 11704637]

12. Czajkowski R, Lei L, Sabala P, Baranska J. ADP-evoked phospholipase C stimulation and adenylyl cyclase inhibition in glioma C6 cells occur through two distinct nucleotide receptors, $\mathrm{P}_{2} \mathrm{Y}_{1}$ and P2Y 12 . FEBS Lett. 2002; 513:179-183. [PubMed: 11904146]

13. Moore D, Iritani S, Chambers J, Emson P. Immunohistochemical localization of the P2Y 1 purinergic receptor in Alzheimer's disease. Neuroreport. 2000; 11:3799-3803. [PubMed: 11117494]

14. Kaiser RA, Buxton IL. Nucleotide-mediated relaxation in guinea-pig aorta: Selective inhibition by MRS2179. Br. J. Pharmacol. 2002; 135:537-545. [PubMed: 11815389]

15. Eckly A, Gendrault JL, Hechler B, Cazenave JP, Gachet C. Differential involvement of the $\mathrm{P}_{2} \mathrm{Y}_{1}$ and $\mathrm{P} 2 \mathrm{YT}$ receptors in the morphological changes of platelet aggregation. Thromb. Haemost. 2001; 85:694-701. [PubMed: 11341507]

16. Jacobson KA. Purine and pyrimidine nucleotide (P2) receptors. Ann. Rep. Med. Chem. 2002; 37:75-84.

17. Nandanan E, Camaioni E, Jang SY, Kim YC, Cristalli G, Herdewijn P, Secrist JA, Tiwari KN, Mohanram A, Harden TK, Boyer JL, Jacobson KA. Structure activity relationships of bisphosphate nucleotide derivatives as $\mathrm{P}_{2} \mathrm{Y}_{1}$ receptor antagonists and partial agonists. J. Med. Chem. 1999; 42:1625-1638. [PubMed: 10229631]

18. Nandanan E, Jang SY, Moro S, Kim H, Siddiqi MA, Russ P, Marquez VE, Busson R, Herdewijn P, Harden TK, Boyer JL, Jacobson KA. Synthesis, biological activity, and molecular modeling of ribose-modified adenosine bisphosphate analogues as $\mathrm{P}_{2} \mathrm{Y}_{1}$ receptor ligands. J. Med. Chem. 2000; 43:829-842. [PubMed: 10715151]

19. Kim HS, Barak D, Harden TK, Boyer JL, Jacobson KA. Acyclic and cyclopropyl anlaogues of adenosine bisphosphate antagonists of the $\mathrm{P}_{2} \mathrm{Y}_{1}$ receptor: Structure activity relationships and receptor docking. J. Med. Chem. 2001; 44:3092-3108. [PubMed: 11543678]

20. Boyer JL, Adams M, Ravi RG, Jacobson KA, Harden TK. 2-Chloro- $N^{6}$-methyl-(N)methanocarba-2-deoxyadenosine- 3,5-bisphosphate is a selective high affinity $\mathrm{P}_{2} \mathrm{Y}_{1}$ receptor antagonist. Br. J. Pharmacol. 2002; 135:2004-2010. [PubMed: 11959804]

21. Fischer B, Boyer JL, Hoyle CHV, Ziganshin AU, Brizzolara AL, Knight GE, Zimmet J, Burnstock G, Harden TK, Jacobson KA. Identification of potent, selective P2Y-purinoceptor agonists: 
Structure-activity relationships for 2-thioether derivatives of adenosine $5^{\prime}$-triphosphate. J. Med. Chem. 1993; 36:3937-3946. [PubMed: 8254622]

22. Boyer JL, Siddiqi S, Fischer B, Romera-Avila T, Jacobson KA, Harden TK. Identification of potent $\mathrm{P}_{2}$ Ypurinoceptor agonists that are derivatives of adenosine $5^{\prime}$-monophosphate. $\mathrm{Br}$. J. Pharmacol. 1996; 118:1959-1964. [PubMed: 8864529]

23. Fischer B, Chulkin A, Boyer JL, Harden TK, Gendron FP, Beaudoin AR, Chapal J, Hillaire-Buys D, Petit P. 2-Thioether 5' $-\mathrm{O}$-(1-thiotriphosphate)adenosine derivatives as new insulin secretagogues acting through P2Y-Receptors. J. Med. Chem. 1999; 42:3636-3646. [PubMed: 10479295]

24. Raboisson P, Baurand A, Cazenave JP, Gachet C, Retat M, Spiess B, Bourguignon JJ. Novel antagonists acting at the $\mathrm{P}_{2} \mathrm{Y}_{1}$ purinergic receptor: Synthesis and conformational analysis using potentiometric and nuclear magnetic resonance titration techniques. J. Med. Chem. 2002; 45:962972. [PubMed: 11831909]

25. Raboisson P, Baurand A, Cazenave JP, Gachet C, Schultz D, Spiess B, Bourguignon JJ. A general approach toward the synthesis of C-nucleoside pyrazolo[1,5-a]-1,3,5-triazines and their $3^{\prime}, 5^{\prime}$ bisphosphate $\mathrm{C}$-nucleotide analogues as the first reported in vivo stable $\mathrm{P}_{2} \mathrm{Y}_{1}$-receptor antagonists. J. Org. Chem. 2002; 67:8063-8071. [PubMed: 12423133]

26. Ingall AH, Dixon J, Bailey A, Coombs ME, Cox D, McInally JI, Hunt SF, Kindon ND, Theobald BJ, Willis PA, Humphries RG, Leff P, Clegg JA, Smith JA, Tomlinson W. Antagonists of the platelet $\mathrm{P}_{2}$ Treceptor: A novel approach to antithrombotic therapy. J. Med. Chem. 1999; 42:213220. [PubMed: 9925726]

27. Brown SG, King BF, Kim YC, Burnstock G, Jacobson KA. Activity of novel adenine nucleotide derivatives as agonists and antagonists at recombinant rat P2X receptors. Drug Devel. Res. 2000; 49:253-259. [PubMed: 22791931]

28. Marquez VE, Siddiqui MA, Ezzitouni A, Russ P, Wang J, Wagner RW, Matteucci MD. Nucleosides with a twist. Can fixed forms of sugar ring pucker influence biological activity in nucleosides and oligonucleotides? J. Med. Chem. 1996; 39:3739-3747. [PubMed: 8809162]

29. Ezzitouni A, Russ P, Marquez VE. (1S,2R)-[(Benzyloxy)- methyl]cyclopent-3-enol. A versatile synthon for the preparation of $4^{\prime}, 1^{\prime}$ a-methano and $1^{\prime}, 1^{\prime}$ a-methano carbocyclic nucleosides. J. Org. Chem. 1997; 62:4870-4873.

30. Siddiqui MA, Ford H Jr, George C, Marquez VE. Synthesis, conformational analysis, and biological activity of a rigid carbocyclic analogue of $2^{\prime}$-deoxyaristeromycin built on a bicyclo[3.1.0]hexane template. Nucleosides Nucleotides. 1996; 15:235-250.

31. Waldo GL, Corbitt J, Boyer JL, Ravi G, Kim HS, Ji XD, Lacy J, Jacobson KA, Harden TK. Quantitation of the $\mathrm{P}_{2} \mathrm{Y}_{1}$ receptor with a high affinity radiolabeled antagonist. Mol. Pharmacol. 2002; 62:1249-1257. [PubMed: 12391289]

32. Yoshimura Y, Moon HR, Choi Y, Marquez VE. Enantioselective synthesis of bicyclo[3.1.0]hexane carbocyclic nucleosides via a lipase-catalyzed asymmetric acetylation. Characterization of an unusual acetal byproduct. J. Org. Chem. 2002; 67:5938-5945. [PubMed: 12182625]

33. Perich JW, Johns RB. Di-tert-butyl $N$, $N$-diethylphosphoramidite. A new phosphitylating agent for the efficient phosphorylation of alcohols. Synthesis. 1988; 2:142-144.

34. Nair V, Fasbender AJ. C-2 Functionalized $N^{6}$-cyclosubstituted adenosines: Highly selective agonists for the adenosine $A_{1}$ receptor. Tetrahedron. 1993; 49:2169-2184.

35. Wilds CJ, Pattanayek R, Pan C, Wawrzak Z, Egli M. Selenium-assisted nucleic acid crystallography: Use of phosphoroselenoates for MAD phasing of a DNA structure. J. Am. Chem. Soc. 2002; 124:14910-14916. [PubMed: 12475332]

36. Robins MJ, Uznanski B. Nucleic acid related compounds. 34. Nonaqueous diazotization of tertbutyl nitrite. Introduction of fluorine, chlorine, and bromine at C-2 of purine nucleosides. Can. J. Chem. 1981; 59:2608-2611.

37. Kim HO. Synthesis of 2-alkyl substituted- $N^{6}$-methyladenine derivatives as potential adenosine receptor ligand. Arch. Pharm. Res. 2001; 6:508-513. [PubMed: 11794524]

38. Coenen HH, Moerlein SM, Stocklin G. No-Carrier-Added Radiohalogenation Methods with Heavy Halogens. Radiochimica Acta. 1983; 34:47-68. 
39. Wilbur DS, Hamlin DK, Srivastava RR, Burns HD. Synthesis and radioiodination of $N$-Boc-p-(tributylstannyl)-lphenylalanine tetrafluorophenyl ester: Preparation of a radiolabeled phenylalanine derivative for peptide synthesis. Bioconjugate Chem. 1993; 4:574-580.

40. Foged C, Halldin C, Hiltunen J, Braestrup C, Thomsen C, Hansen HC, Suhara T, Pauli S, Swahn CG, Karlsson P, Larsson S, Farde L. Development of 123I-labeled NNC 13-8241 as a radioligand for SPECT visualization of benzodiazepine receptor binding. Nucl. Med. Biol. 1996; 23:201-209. [PubMed: 8782227]

41. Rasmussen M, Leonard NJ. The synthesis of 3-(2'-Deoxy-Dribofuranosyl) adenine. Application of a new protecting group, Pivaloyloxymethyl (Pom). J. Am. Chem. Soc. 1967; 89, 9(21):5439-5445.

42. Baranowska-Kortylewicz J, Helseth LD, Lai J, Schneiderman MH, Schneiderman GS, Dalrymple GV. Radiolabeling kit/generator for 5-radiohalogenated uridines. Journal of Labeled Compounds and Radiopharceuticals. 1994; 34:513-522.

43. Suzuki M, Doi H, Bjorkman M, Andersson Y, Langstom B, Watanabe Y, Noyori R. Rapid coupling of methyl iodide with aryltributylstannanes mediated by palladium (0) complexes: A general protocol for the synthesis of ${ }^{11} \mathrm{CH}^{3}$-labeled PET tracers. Chem. Eur. J. 1997; 3:2039-2042.

44. Chaconas G, v. d. Sande JH. 5' -32 P labeling of RNA and DNA restriction fragments. Methods Enzymol. 1980; 65:75-85. [PubMed: 6154877]

45. Xu B, Stephens A, Kirschenheuter G, Greslin AF, Cheng X, Sennelo J, Cattaneo M, Zighetti ML, Chen A, Kim SA, Kim HS, Bischofberger N, Cook G, Jacobson KA. Acyclic analogues of adenosine bisphosphates as $\mathrm{P} 2 \mathrm{Y}$ receptor antagonists: Phosphate substitution leads to multiple pathways of inhibition of platelet aggregation. J. Med. Chem. 2002; 45:5694-5709. [PubMed: 12477353]

46. Lee K, Cass C, Jacobson KA. Synthesis using ring closure metathesis and effect on nucleoside transport of a (N)-methanocarba $S$-(4-nitrobenzyl)thioinosine derivative. Org. Lett. 2001; 3:597599. [PubMed: 11178834]

47. Harden TK, Hawkins PT, Stephens L, Boyer JL, Downes P. Phosphoinositide hydrolysis by guanosine $5^{\prime}$-[gammathio] triphosphate-activated phospholipase $\mathrm{C}$ of turkey erythrocyte membranes. Biochem. J. 1988; 252:583-593. [PubMed: 2843174]

48. Boyer JL, Downes CP, Harden TK. Kinetics of activation of phospholipase C by P2Y purinergic receptor agonists and guanine nucleotides. J. Biol. Chem. 1989; 264:884-890. [PubMed: 2910869] 


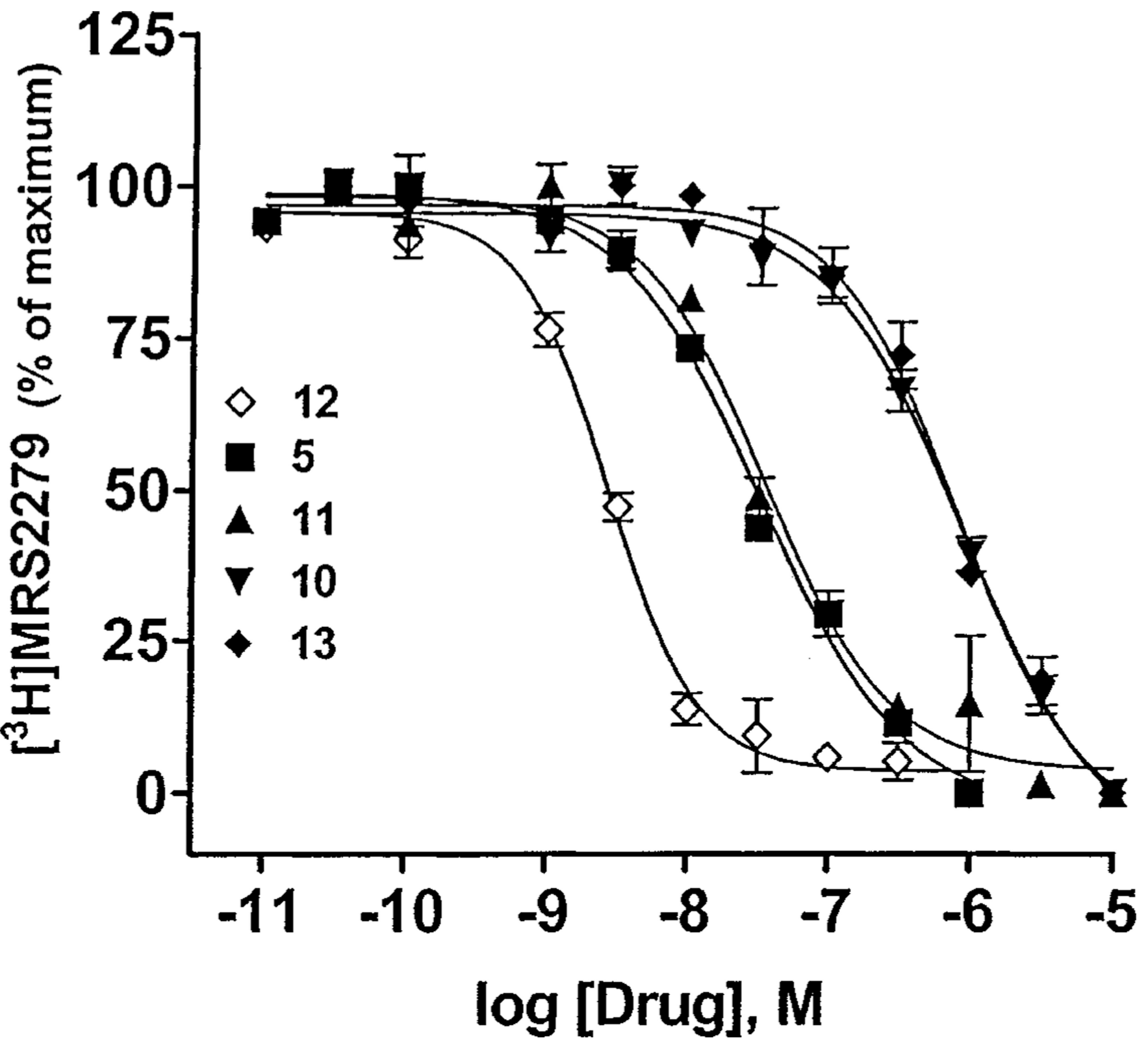

Figure 1.

Inhibition of $\left[{ }^{3} \mathrm{H}\right] \mathbf{5}$ binding to human $\mathrm{P}_{2} \mathrm{Y}_{1}$ receptors by 2 -substituted analogues. $\left[{ }^{3} \mathrm{H}\right] \mathbf{5}$ binding assays were carried out as described in the Experimental Section using Sf9 membranes expressing recombinant human $\mathrm{P}_{2} \mathrm{Y}_{1}$ receptor. The data are presented as percent of total radioligand binding measured in the presence of the indicated concentrations of 2chloro (5), 2-fluoro (10), 2-bromo (11), 2-iodo (12), and 2-methylthio (13) $N^{6}$-methyl substituted analogues. The data are the mean of triplicate determinations, and the results are consistent with those obtained in three separate experiments. 

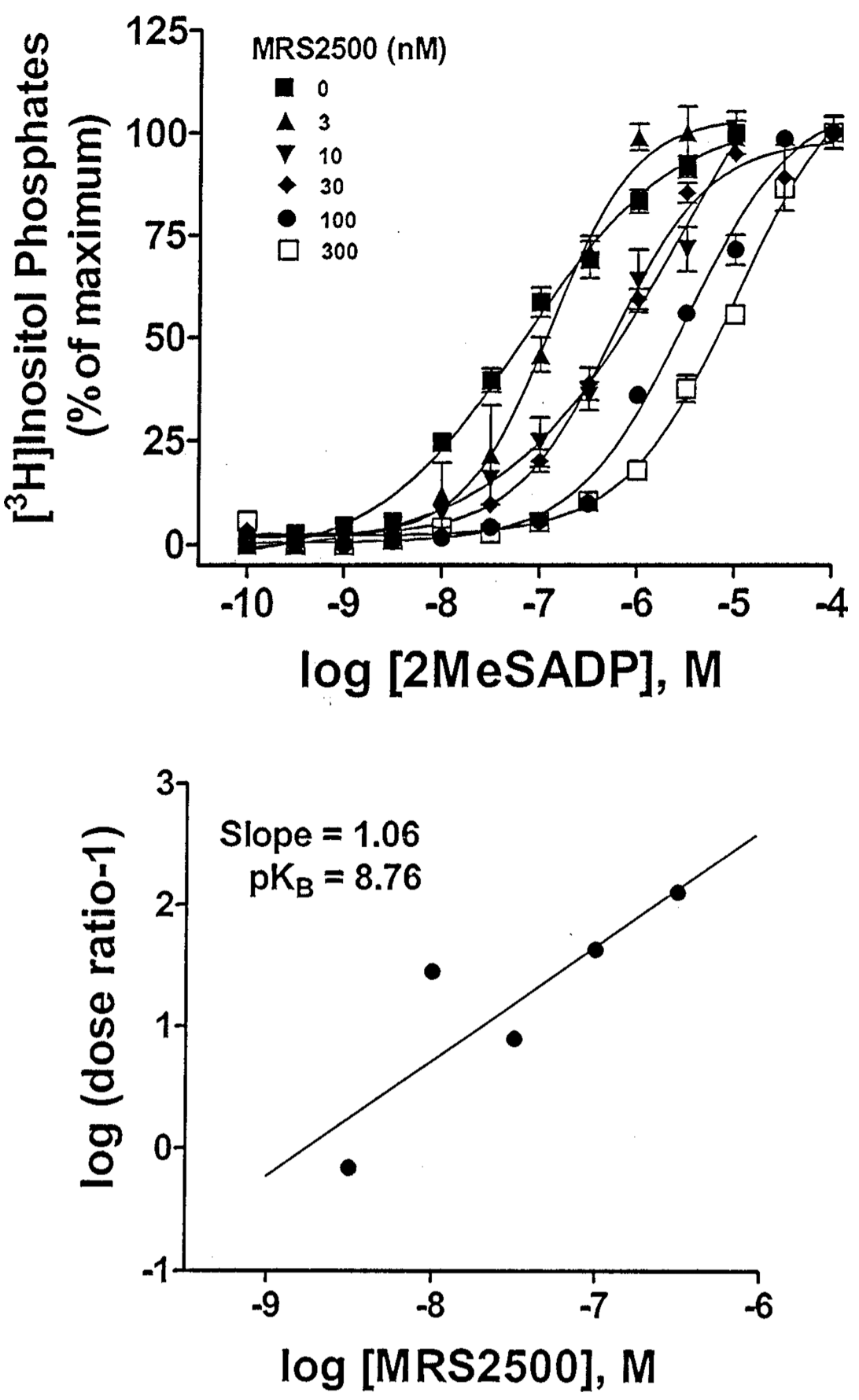

Figure 2.

Competitive antagonism of $2 \mathrm{MeSADP}$-promoted activation of the human $\mathrm{P}_{2} \mathrm{Y}_{1}$ receptor. Phospholipase $\mathrm{C}$ activity was measured as described in the Experimental Section in 1321N1 human astrocytoma cells stably expressing the human $\mathrm{P}_{2} \mathrm{Y}_{1}$ receptor. Top panel: assays were in the presence of the indicated concentrations of the agonist 2Me-SADP alone or in the presence of the potent antagonist $\mathbf{1 2}$ at 3, 10,30, 100, and $300 \mathrm{nM}$. The data are the means of triplicate determinations and are representative of results obtained in four separate experiments. Lower panel: Schild analysis of antagonism by $\mathbf{1 2}$ of inositol phosphate 
accumulation in $1321 \mathrm{~N} 1$ human astrocytoma cells stably expressing the human $\mathrm{P} \mathrm{Y}_{1}$ receptor, stimulated by 2-MeS-ADP. 


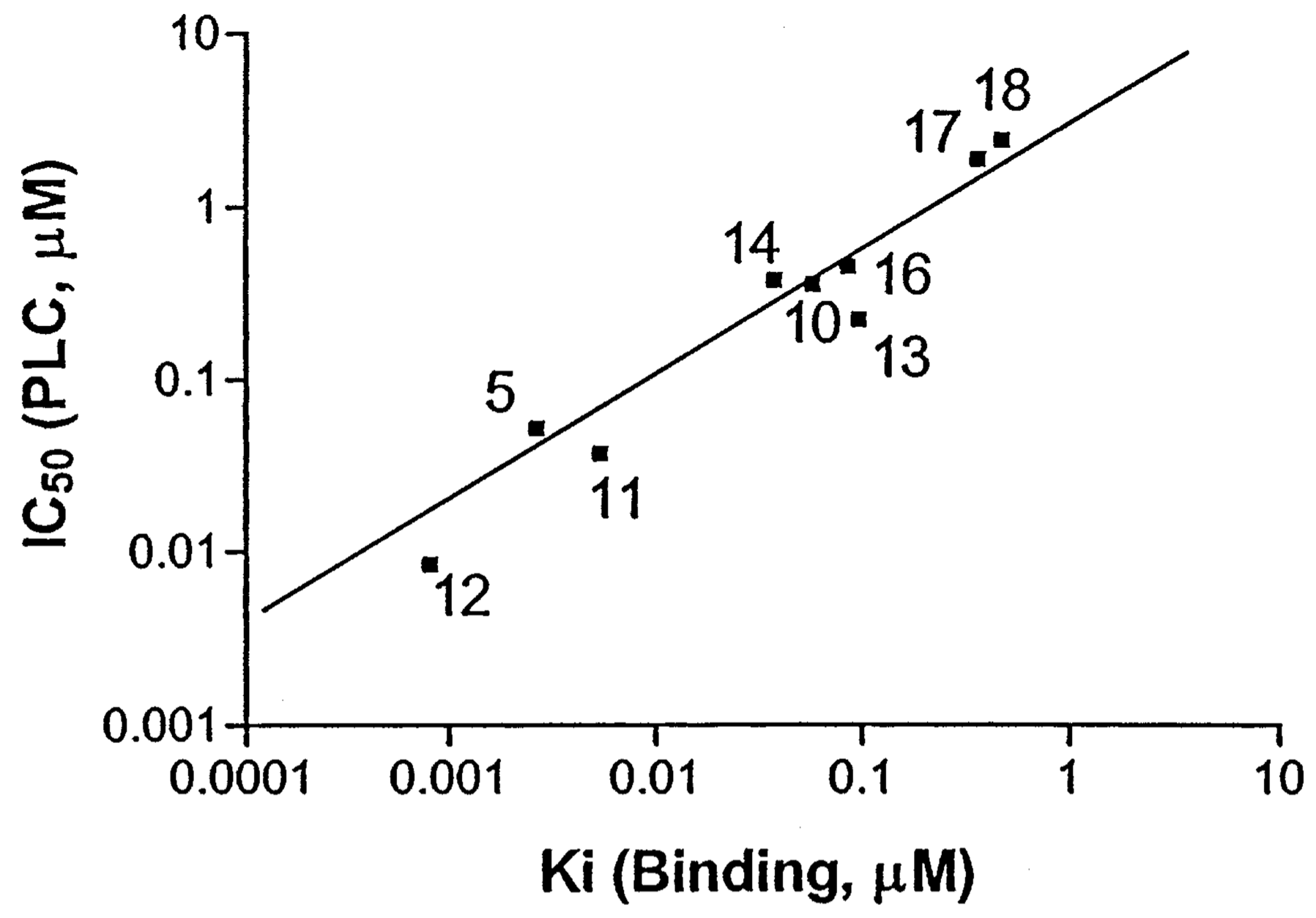

Figure 3.

Correlation of binding affinities at the human $\mathrm{P} 2 \mathrm{Y}_{1}$ receptor expressed in Sf9 cells and functional potencies as $\mathrm{P}_{2} \mathrm{Y}_{1}$ receptor antagonists (measuring inhibition of inositol phosphate accumulation in $1321 \mathrm{~N} 1$ human astrocytoma cells stably expressing the human $\mathrm{P}_{2} \mathrm{Y}_{1}$ receptor, stimulated by $30 \mathrm{nM}$ 2-MeS-ADP). 

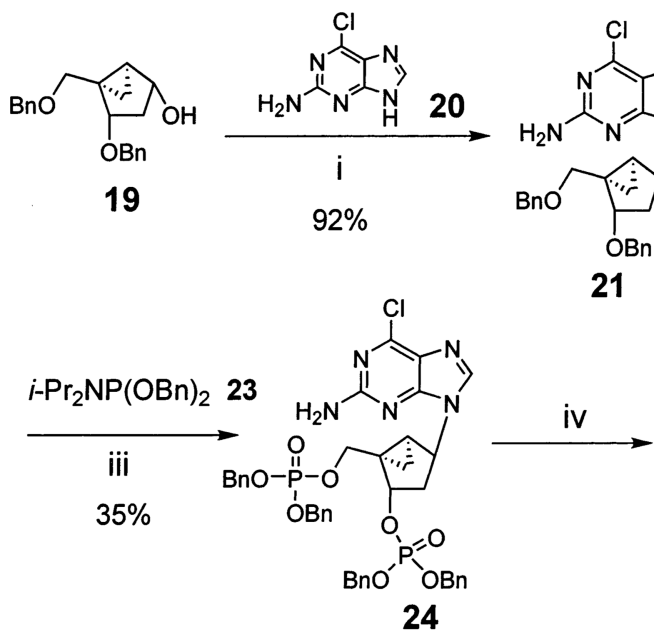

24

26

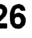<smiles>CC#CC(C)Cn1cnc2c(Cl)nc(N)nc21</smiles>

22

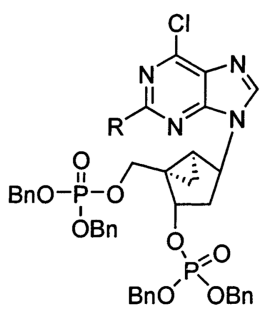

$$
\begin{array}{ll}
25 & R=I, 37 \% \\
26 & R=M e S, 64 \% \\
27 & R=M e S e, 38 \%
\end{array}
$$
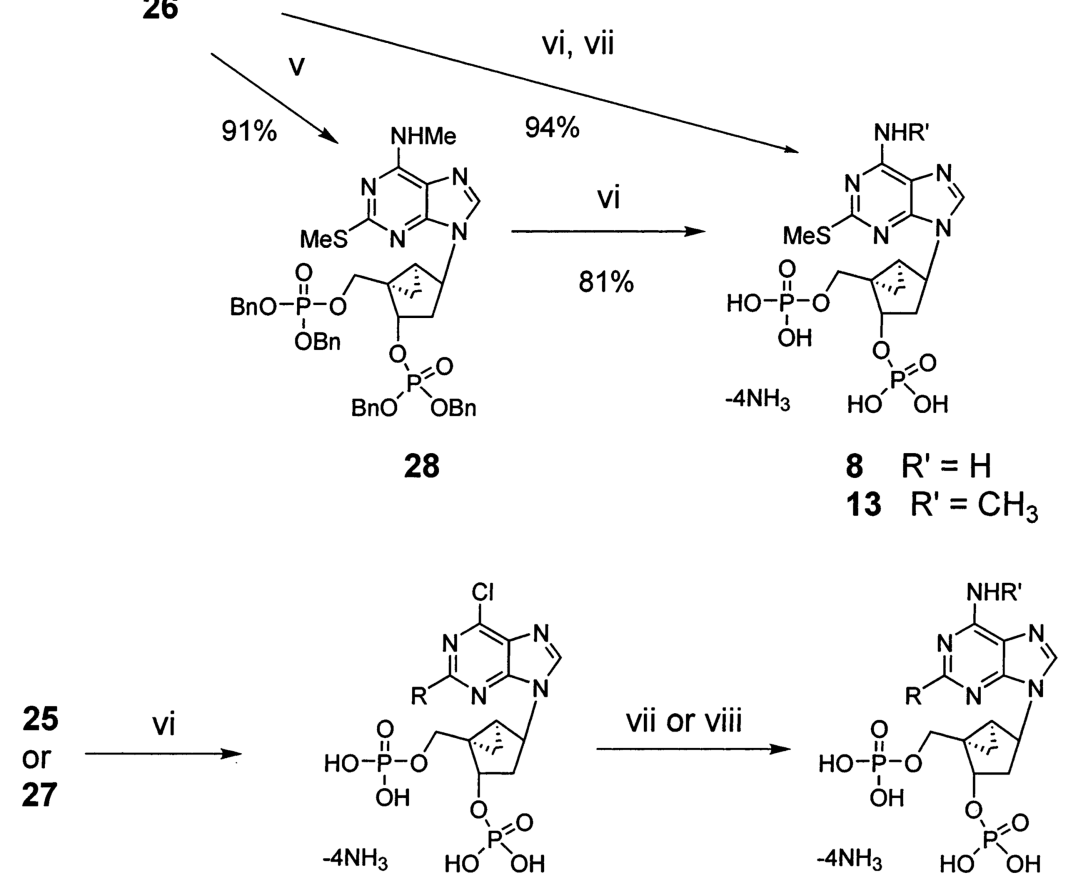

$29 \mathrm{R}=\mathrm{I}, 60 \%$

$7 \mathrm{R}=\mathrm{I}, \mathrm{R}^{\prime}=\mathrm{H}, 54 \%$

$30 \mathrm{R}=\mathrm{MeSe}, 28 \%$

$12 \mathrm{R}=\mathrm{I}, \mathrm{R}^{\prime}=\mathrm{Me}, 20 \%$

$14 \mathrm{R}=\mathrm{MeSe}, \mathrm{R}^{\prime}=\mathrm{Me}, 79 \%$

Scheme $1^{a}$

${ }^{a}$ Reagents: (i) DIAD, $\mathrm{Ph}_{3} \mathrm{P}$, rt, 2-amino-6-chloropurine; (ii) $\mathrm{BCl}_{3}, \mathrm{CH}_{2} \mathrm{Cl}_{2},-40{ }^{\circ} \mathrm{C}$; (iii) $1 H$ tetrazole then $m$-CPBA; (iv) $\mathrm{CH}_{2} \mathrm{I}_{2}$, or MeSSMe, or MeSeSeMe, $t$-BuONO, MeCN; (v) $\mathrm{MeNH}_{2} / \mathrm{THF}$; (vi) $\mathrm{BCl}_{3}, \mathrm{CH}_{2} \mathrm{Cl}_{2}, 5^{\circ} \mathrm{C}$; (vii) $\mathrm{NH}_{3} / \mathrm{H}_{2} \mathrm{O}, 70{ }^{\circ} \mathrm{C}, 2 \mathrm{~h}$; (viii) $\mathrm{MeNH}_{2} / \mathrm{H}_{2} \mathrm{O}$. 


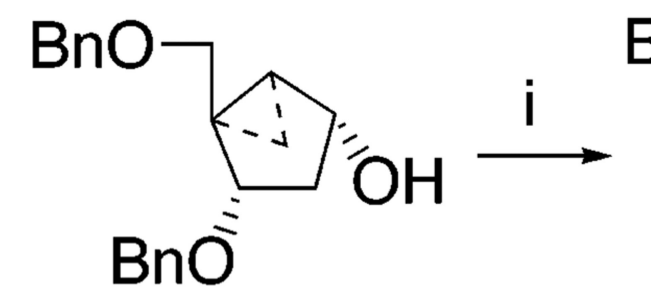

19

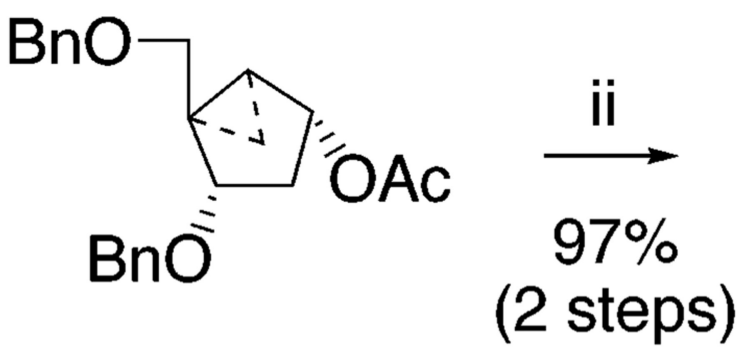

31

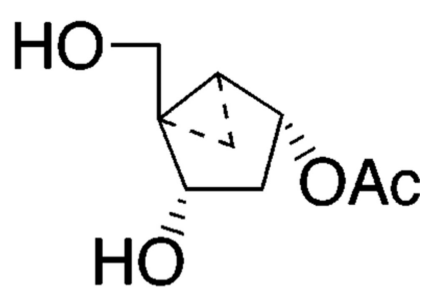

32

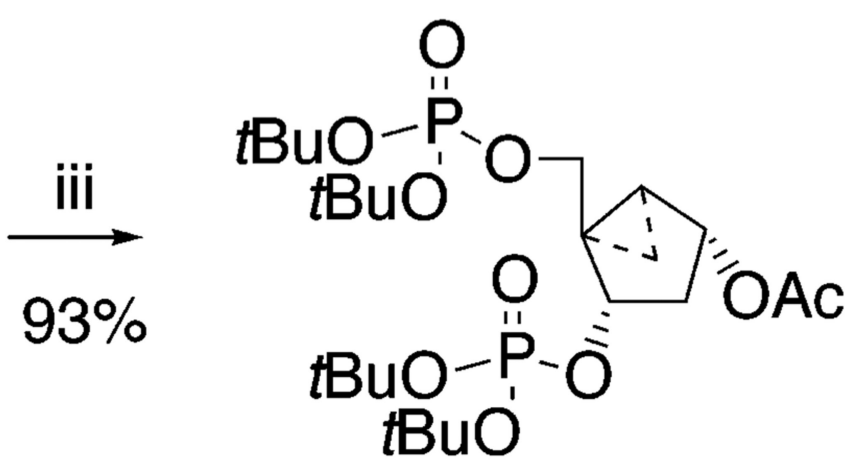

33

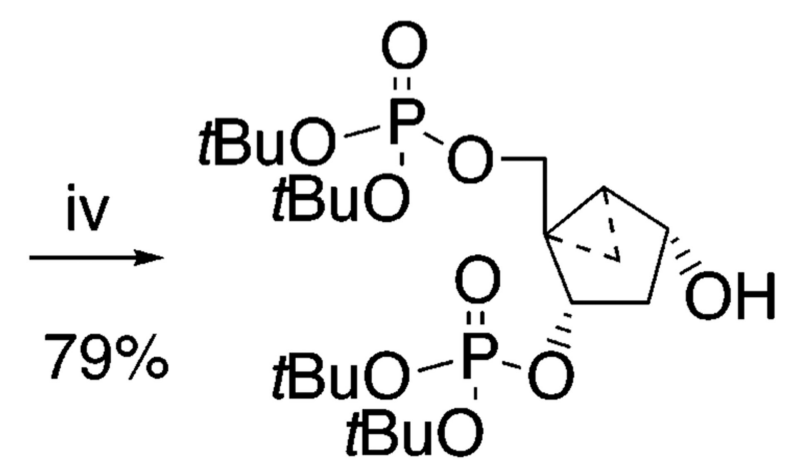

34

Scheme $2^{a}$

${ }^{a}$ Reagents: (i) $\mathrm{Ac}_{2} \mathrm{O}$, cat. DMAP, TEA, $\mathrm{CH}_{2} \mathrm{Cl}_{2}, \mathrm{rt}, 4$ h; (ii) wet $5 \% \mathrm{Pd} / \mathrm{C}, \mathrm{H}_{2}, \mathrm{MeOH}, \mathrm{rt}, 4$ $\mathrm{h}$; (iii) $(t \text {-BuO) })_{2} \mathrm{PNEt}$, tetrazole, THF, rt, $1 \mathrm{~h}$ then $m$-CPBA, -78 to $0{ }^{\circ} \mathrm{C}, 20 \mathrm{~min}$; (iv) $\mathrm{K}_{2} \mathrm{CO}_{3}, \mathrm{MeOH}, \mathrm{rt}, 2 \mathrm{~h}$. 
<smiles>Nc1nc(Cl)c2nc[nH]c2n1</smiles><smiles>[R]c1nc(NC)c2nc[nH]c2n1</smiles>

20

$$
\begin{aligned}
& 35 \mathrm{R}=\mathrm{Br}(87 \%) \\
& 36 \mathrm{R}=\mathrm{F}(91 \%)
\end{aligned}
$$

$37 \mathrm{R}=\mathrm{F}(80 \%)$

$38 \mathrm{R}=\mathrm{Br}(93 \%)$

Scheme $3^{a}$

${ }^{a}$ Reagents: (i) $\mathrm{SbBr}_{3} / \mathrm{CH}_{2} \mathrm{Br}_{2}, t$-Bu nitrite; (ii) $\mathrm{HF} /$ pyridine, $t$-Bu nitrite; (iii) $\mathrm{CH}_{3} \mathrm{NH}_{2} / \mathrm{THF}$ or $\mathrm{H}_{2} \mathrm{O}$. 


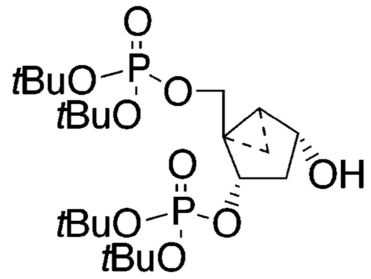

34

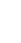

$37 \mathrm{R}=\mathrm{F}, \mathrm{R}^{\prime}=\mathrm{NHCH}_{3}$

$38 \mathrm{R}=\mathrm{Br}, \mathrm{R}^{\prime}=\mathrm{NHCH}_{3}$

$39 \mathrm{R}=\mathrm{I}, \mathrm{R}^{\prime}=\mathrm{NHCH}_{3}$

$40 \mathrm{R}=\mathrm{CH}_{3}, \mathrm{R}^{\prime}=\mathrm{NHCH}_{3}$

$41 \mathrm{R}=1$-hexenyl, $\mathrm{R}^{\prime}=\mathrm{NHCH}_{3}$

$42 \mathrm{R}=1$-hexynyl, $\mathrm{R}^{\prime}=\mathrm{NHCH}_{3}$

$43 \mathrm{R}=\mathrm{I}, \mathrm{R}^{\prime}=\mathrm{Cl}$

i or ii

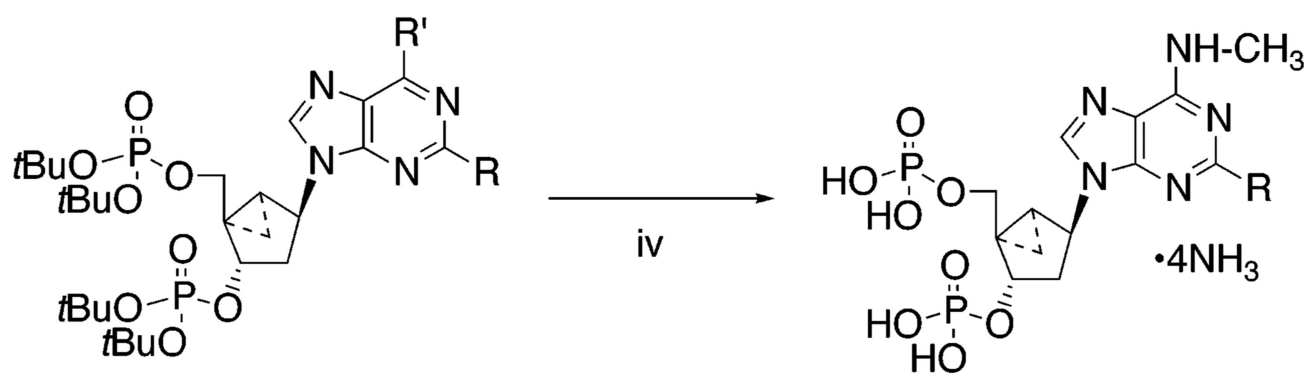
$\mathrm{R}=$
44, F $(47 \%)$
$\left(\mathrm{R}^{\prime}=\mathrm{NHCH}_{3}\right)$
45, $\mathrm{Br}(23 \%)$
$10, \mathrm{~F} \quad(36 \%)$
$11, \mathrm{Br} \quad(58 \%)$
12, I (55\%)
$15, \mathrm{CH}_{3} \quad(73 \%)$
47, $\mathrm{CH}_{3} \quad(49 \%)$
iii $\longrightarrow$ 48, hexanyl (88\%)
16, hexanyl $(69 \%)$
17, 1-hexenyl (68\%)
50, 1-hexynyl (72\%)
18, 1-hexynyl (73\%)
$\mathrm{R}=$
51 , iodo
(57\%)
$\left(\mathrm{R}^{\prime}=\mathrm{Cl}\right)$

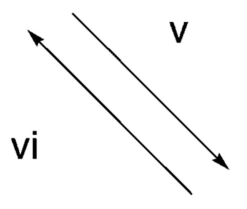

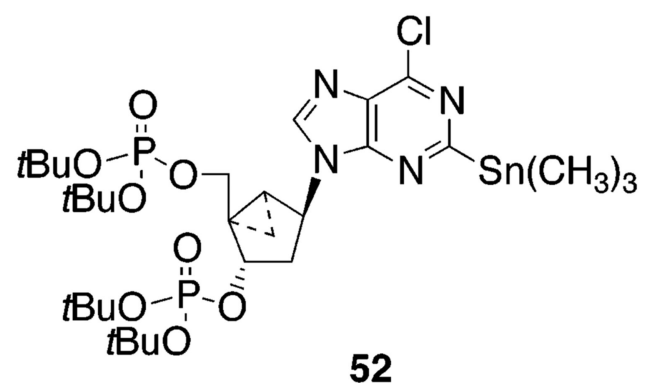

Scheme $4^{a}$

${ }^{a}$ Reagents: (i) 2-substituted (iodo, methyl, 2-hexenyl) 6-methylaminopurine or 2-iodo-6chloropurine, $\mathrm{Ph}_{3} \mathrm{P}, \mathrm{DEAD}$, THF, rt, $2 \mathrm{~h}$; (ii) 2-substituted (fluoro, bromo, or 2-hexynyl) 6methylaminopurine, $\mathrm{Ph}_{3} \mathrm{P}$, DIAD, THF; (iii) $5 \% \mathrm{Pd} / \mathrm{C}, \mathrm{H}_{2}, \mathrm{MeOH}$, rt, $2 \mathrm{~h}$; (iv) $5 \%$ TFA in $\mathrm{CH}_{2} \mathrm{Cl}_{2}, \mathrm{rt}, 2 \mathrm{~h}$; (v) $\mathrm{PdCl}_{2}\left(\mathrm{PPh}_{3}\right)_{2}, \mathrm{Me}_{3} \mathrm{SnSnMe}_{3}$, dioxane, $60{ }^{\circ} \mathrm{C}$; (vi) $\mathrm{I}_{2}, \mathrm{THF}$, rt. 
<smiles>CC(C)(C)C(=O)OCn1cnc2c(Cl)nc(N)nc21</smiles>

20

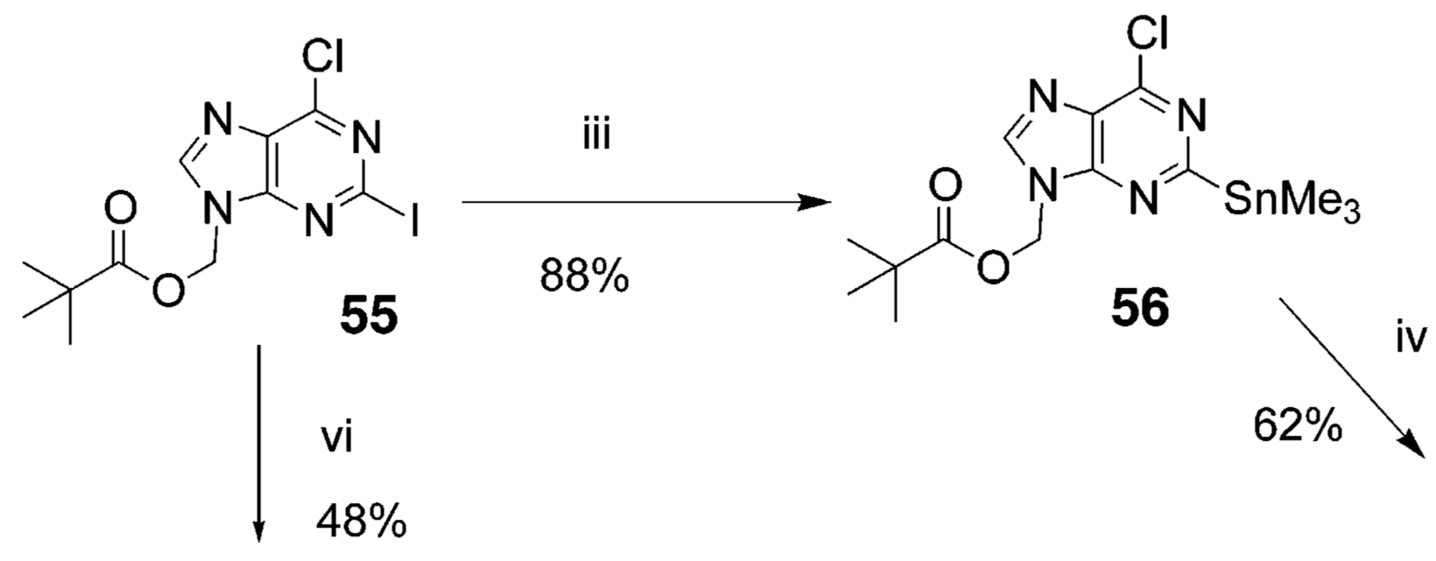<smiles>Clc1nc(I)nc2[nH]cnc12</smiles><smiles>CNc1nc(C)nc2[nH]cnc12</smiles>

40

Scheme $5^{a}$

${ }^{a}$ Reagents: (i) $\mathrm{K}_{2} \mathrm{CO}_{3}$, DMSO-DMF, rt, $3 \mathrm{~d}$; (ii) $\mathrm{CH}_{2} \mathrm{I}_{2}, t$-BuONO, acetonitrile, $60{ }^{\circ} \mathrm{C}, 2.5$ h; (iii) $\mathrm{PdCl}_{2}\left(\mathrm{PPh}_{3}\right)_{2}, \mathrm{Me}_{3} \mathrm{SnSnMe}_{3}$, dioxane, $100{ }^{\circ} \mathrm{C}, 5 \mathrm{~h}$; (iv) $\mathrm{Pd}_{2}(\mathrm{dba})_{3}, \mathrm{P}(o \text {-tol })_{3}, \mathrm{CuBr}$, $\mathrm{K}_{2} \mathrm{CO}_{3}$, MeI, DMF, $60^{\circ} \mathrm{C}, 3 \mathrm{~h}$; (v) $\mathrm{CH}_{3} \mathrm{NH}_{2} / \mathrm{THF}$, rt, $22 \mathrm{~h}$; (vi) $5 \mathrm{~N} \mathrm{NaOH}, i-\mathrm{PrOH}$, rt, $3 \mathrm{~d}$. 


<smiles>CNc1nc(Cl)nc2c1ncn2C1CC(O)C2CC1(CO)C2</smiles>

Scheme $6^{a}$

${ }^{a}$ Reagents: (i) polynucleotide kinase, ATP; (ii) polynucleotide kinase, alone. 


\section{Table 1}

In Vitro Pharmacological Data at Human P2Y $\mathrm{Y}_{1}$ Receptors for Inhibition of PLC Elicited by $30 \mathrm{nM}$ 2-MeSADP (receptor expressed in $1321 \mathrm{~N}$ astrocytoma cells) and in Binding (receptor expressed in Sf9 cells) ${ }^{31 d}$

\begin{tabular}{rlccc}
\hline compd & $\mathbf{R}$ & $\mathbf{R}^{\prime}$ & $\begin{array}{c}\boldsymbol{K}_{\mathbf{i}}, \mathbf{n M}^{\boldsymbol{a}} \\
\mathbf{7}\end{array}$ I & $\begin{array}{c}\text { antagonism, } \\
\mathbf{I C}_{\mathbf{5 0}}, \mathbf{n M}^{\boldsymbol{b}}\end{array}$ \\
$\mathbf{8}$ & $\mathrm{SCH}_{3}$ & $\mathrm{H}$ & $12.6 \pm 0.3$ & $87 \pm 1$ \\
$\mathbf{9}$ & $\mathrm{H}$ & $\mathrm{CH}_{3}$ & $17.6 \pm 2.7$ & $157 \pm 60$ \\
$\mathbf{1 0}$ & $\mathrm{F}$ & $\mathrm{CH}_{3}$ & $45 \pm 21$ & $356 \pm 122$ \\
$\mathbf{5}^{c}$ & $\mathrm{Cl}$ & $\mathrm{CH}_{3}$ & $2.5 \pm 0.4$ & $52 \pm 1$ \\
$\mathbf{1 1}$ & $\mathrm{Br}$ & $\mathrm{CH}_{3}$ & $5.1 \pm 0.6$ & $37 \pm 6$ \\
$\mathbf{1 2}$ & $\mathrm{I}$ & $\mathrm{CH}_{3}$ & $0.78 \pm 0.08$ & $8.4 \pm 0.8$ \\
$\mathbf{1 3}$ & $\mathrm{SCH}$ & $\mathrm{CH}_{3}$ & $91 \pm 12$ & $221 \pm 30$ \\
$\mathbf{1 4}$ & $\mathrm{SeCH}$ & $\mathrm{CH}_{3}$ & $35 \pm 4$ & $377 \pm 154$ \\
$\mathbf{1 5}$ & $\mathrm{CH}_{3}$ & $\mathrm{CH}_{3}$ & $3.6 \pm 0.7$ & $49 \pm 1$ \\
$\mathbf{1 6}$ & $\left(\mathrm{CH}_{2}\right)_{5} \mathrm{CH}_{3}$ & $\mathrm{CH}_{3}$ & $80 \pm 10$ & $452 \pm 221$ \\
$\mathbf{1 7}$ & trans-CH=CH$-\left(\mathrm{CH}_{2}\right)_{3} \mathrm{CH}_{3}$ & $\mathrm{CH}_{3}$ & $330 \pm 70$ & $1870 \pm 590$ \\
$\mathbf{1 8}$ & $\mathrm{C} \equiv \mathrm{C}-\left(\mathrm{CH}_{2}\right)_{3} \mathrm{CH}_{3}$ & $\mathrm{CH}_{3}$ & $430 \pm 200$ & $2400 \pm 600$ \\
\hline
\end{tabular}

${ }^{a}$ The affinities were determined by using $\left[{ }^{3} \mathrm{H}\right] 5$ in a radioligand binding assay, as recently described. ${ }^{31}$ The human $\mathrm{P} 2 \mathrm{Y}_{1}$ receptor was expressed to high levels in Sf9 insect cells with a recombinant baculovirus. Membranes prepared from these cells were incubated for 30 min at $4{ }^{\circ} \mathrm{C}$ in the presence of $\sim 20 \mathrm{nM}\left[{ }^{3} \mathrm{H}\right] \mathbf{5}$.

${ }^{b}$ Antagonist IC50 values (mean \pm standard error) represent the concentration needed to inhibit by $50 \%$ the effect elicited by $30 \mathrm{nM} 2-\mathrm{MeSADP}$. The percent of maximal inhibition is equal to 100 minus the residual fraction of stimulation at the highest antagonist concentration. $N=3$, unless otherwise indicated in parentheses.

${ }_{5}$, MRS 2279; 12, MRS 2500 .

${ }^{d}$ Mean \pm SEM given for three separate determinations. None of the compounds displayed agonist effects. $\mathrm{R}$ and $\mathrm{R}^{\prime}$ are defined in Scheme 1. 